Discussion

Papers

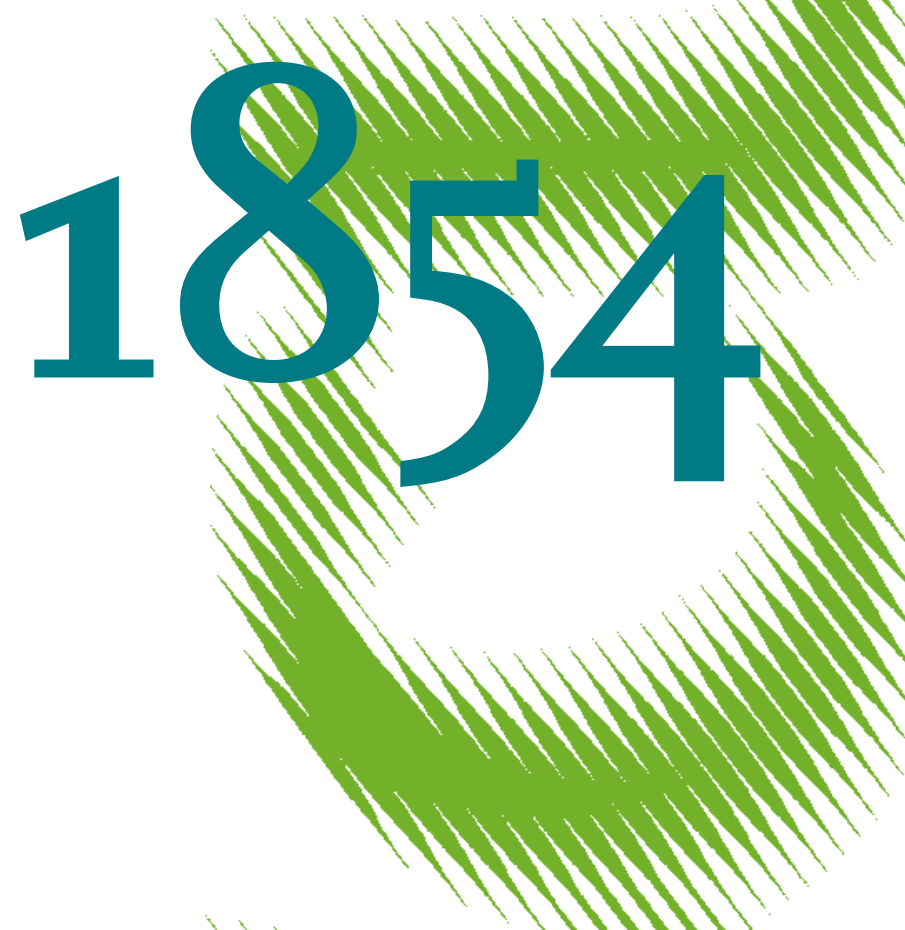

The Dynamic Impact of FX Interventions on Financial Markets 
Opinions expressed in this paper are those of the author(s) and do not necessarily reflect views of the institute.

IMPRESSUM

(C) DIW Berlin, 2020

DIW Berlin

German Institute for Economic Research

Mohrenstr. 58

10117 Berlin

Tel. +49 (30) $89789-0$

Fax +49 (30) $89789-200$

http://www.diw.de

ISSN electronic edition 1619-4535

Papers can be downloaded free of charge from the DIW Berlin website:

http://www.diw.de/discussionpapers

Discussion Papers of DIW Berlin are indexed in RePEc and SSRN:

http://ideas.repec.org/s/diw/diwwpp.html

http://www.ssrn.com/link/DIW-Berlin-German-Inst-Econ-Res.html 


\title{
The dynamic impact of FX interventions on financial markets
}

\author{
Lukas Menkhoff, Malte Rieth and Tobias Stöhr
}

\begin{abstract}
Evidence on the effectiveness of FX interventions is either limited to short horizons or hampered by debatable identification. We address these limitations by identifying a structural vector autoregressive model for the daily frequency with an external instrument. Generally, we find, for freely floating currencies, that FX intervention shocks significantly affect exchange rates and that this impact persists for months. The signaling channel dominates the portfolio channel. Moreover, interest rates tend to fall in response to sales of the domestic currency, whereas stock prices of large (exporting) firms increase after devaluation of the domestic currency.
\end{abstract}

JEL-Classification: F 31 (foreign exchange); F 33 (international monetary arrangements); E 58 (central banks and their policies)

Keywords: $\quad$ Foreign exchange intervention; structural VAR; exchange rates; interest rates; stock prices

March 2020

We thank participants at several seminars, in particular Lukas Boer, Dario Caldara, Rasmus Fatum, Georgios Georgiadis, Marek Jarocinski, Peter Karadi, Mathias Klein, Alexander Kriwoluzky, Christopher Neely, Mauricio Villamizar, Georg Weizsäcker, two anonymous referees and the editor (Olivier Coibion) for very helpful comments. We also gratefully acknowledge financial support by the German Research Foundation (DFG, ME 1070/12 and stimulus by grant CRC 190).

Lukas Menkhoff, Humboldt-University Berlin, and DIW Berlin (German Institute for Economic Research), 10108 Berlin, Germany; lmenkhoff@diw.de.

Malte Rieth, DIW Berlin (German Institute for Economic Research), 10108 Berlin, Germany; mrieth@diw.de.

Tobias Stöhr, Kiel Institute for the World Economy, 24100 Kiel, Germany, and DIW Berlin; tobias.stoehr@ifw-kiel.de. 


\section{Introduction}

Foreign exchange (FX) interventions are increasingly prominent. Policy makers, especially those from the International Monetary Fund (IMF), are much more open to applying FX interventions as a policy tool than before (IMF, 2012; Blanchard et al., 2015; Ghosh et al., 2017), without glamorizing it (Obstfeld et al., 2019). In line with this new appreciation of interventions, it is documented that central banks all over the world see this instrument as an integral part of their toolkit and apply it accordingly (Neely, 2008; Mohanty and Berger, 2013; Frankel, 2016). The mainstream policy stance is complemented by a set of theoretical papers building on existing literature (such as Vitale, 2003). These show that FX interventions can have positive effects for the economies applying them (Gabaix and Maggiori, 2015; Hassan et al., 2016; Fanelli and Straub, 2017; Basu et al., 2018; Chang, 2018; Cavallino, 2019).

In contrast to these rather homogeneous positions of policy makers and theorists, there is less progress on the empirical front. We take stock of this literature later on. In summary, the most convincing evidence about the effectiveness of FX interventions may be based on event studies. An attractive feature of this approach is the use of daily (e.g., Fatum and Hutchison, 2003; Fratzscher et al., 2019) or intra-daily data (e.g., Dominguez, 2003), which reduces the risk of reverse causality and of confounding factors. However, event studies, by definition, provide evidence over shorter horizons, such as a few days. Moreover, they typically treat actual interventions as the true policy shocks, while it is likely that actual interventions measure such shocks with error, for example, because communication accompanies the actual intervention.

Studies addressing the longer-term impact of interventions by using lower frequency data (e.g., Blanchard et al., 2015) need to rely on tenuous assumptions (e.g., on instruments) and imprecise proxies of true intervention data. Studies improving on the estimation method are limited to quite specific country cases (e.g., Kearns and Rigobon, 2005). Thus, missing is an 
approach that at least partially overcomes the inherent trade-offs by deriving longer-term predictions of the intervention impact based on daily data and a powerful estimation method.

Therefore, in this paper we use structural vector autoregressions (SVAR) for the daily frequency identified with an external instrument to study the dynamic effects of FX interventions on financial markets. This methodology, also called a Proxy-SVAR, is developed in Stock and Watson (2012) and Mertens and Ravn (2013), and is new to the FX intervention literature. It preserves the attractive features of the event study design and of models for lower frequency data but addresses some of their key limitations. First, it views the actual interventions as a noisy measure of latent intervention shocks. By accounting for several forms of measurement error, it reduces the attenuation bias present in estimates from models treating the actual interventions as a one-to-one mapping to the intervention shocks. Second, it allows quantifying the persistence of the effects of FX interventions, which is of key importance for macroeconomists and policy makers. Third, by relying on higher frequency data, it reduces the risk of confounding factors, reverse causality, and mismeasurement of policy-induced changes in reserves plaguing identification strategies for lower frequency data.

We study some of the most important currencies in the world economy, i.e. Japanese Yen, US-Dollar, Euro, and British Pound. We select these currencies because they represent flexible exchange rate regimes (Ilzetzki et al., 2019), their markets are liquid, and intervention data are publicly available (or can be inferred from press reports for the Euro). In particular, we focus on Japanese and US interventions between 1991 and 2017 because these countries were relatively frequent interveners, giving us a sufficient number of actual interventions to obtain reliable estimates. In order to examine the generalizability of results, we repeat the analysis for the Euro Area and the UK, while acknowledging that we have only a handful of interventions for these two cases in the sample. 
Using daily data limits the set-up of the SVAR to financial variables, but from a macroeconomic viewpoint this is not problematic. Given the high number of time-series observations from the daily sampling frequency, we can include many lags of the endogenous variables and still estimate the autoregressive part of the model reliably without running into the curse of dimensionality. This allows us to say something about the intervention impact at macroeconomically relevant horizons of several months or even quarters.

The crucial issue for the identification approach is the instrument. We propose using the intervention direction on the first day of an intervention sequence as a proxy for latent intervention shocks. The central assumption is that concurrent news about the economy do not affect the decision to start and the direction of a new sequence. This decision typically requires the coordination between the central bank and the treasury, the latter having the legal lead on intervention policy, and is determined based on developments occurring over days or even longer horizons. Moreover, in a regime of largely floating exchange rates, there is no clear and communicated policy on exchange rate stabilization. So, the exact intervention days are largely exogenous at the daily frequency. Of course, interventions may be more or less probable, as argued by Frankel (2019), but they are not anticipated with any certainty. As interventions often occur in sequences, this argument holds in particular for the first day, or the first intervention during a day, but less so for subsequent interventions. We provide detailed evidence on this argument in Section 2.2 and note that high-frequency studies reveal that most of an intervention's impact comes from the first intervention (e.g. Fischer and Zurlinden, 1999; Payne and Vitale, 2003), indicating that these surprise the market but less so subsequent interventions.

We have four main findings. First, a surprise purchase of foreign currency by Japanese or US authorities depreciates the domestic currency significantly. For Japan, a one standard deviation intervention shock, corresponding to purchases of 1.7 billion USD, leads to an immediate depreciation of about $0.2 \%$ relative to the US-Dollar, Pound and Euro. A comparison 
with previous findings (e.g., Kearns and Rigobon, 2005; Chen et al., 2012), and considering the same sample (shorter than our full sample), shows that our estimate is at the upper end of the available evidence, consistent with the argument that accounting for measurement error reduces the attenuation bias and leads to more precise estimates of the efficacy of FX interventions. Furthermore, the estimates reveal that intervention shocks explain up to $12 \%$ of Yen fluctuations on average. They also contributed to prevent an appreciation of the Yen during certain episodes, in particular when interventions reached a hitherto unseen frequency and level in 2003/04 and following the massive Tohoku earthquake in 2011. In contrast, US intervention shocks play only a minor role for the evolution of the US-Dollar. At the same time, they are more effective. We attribute this greater efficacy of interventions to some extent to interest rates being less constrained by the zero lower bound in the US during the sample, and the corresponding better functioning of the signaling channel, than in Japan, where policy rates approached zero already in the early 2000s.

Second, the effects of FX interventions are highly persistent. The shocks move exchange rates significantly for up to four quarters in the case of Japan and for about one quarter in the US.

Third, we aim for disentangling the total FX intervention impact into its two main components: the portfolio channel and the signaling channel. We implement two estimation approaches that consistently suggest that for Japan the signaling channel dominates the portfolio channel with a share of about two thirds to one third of the overall impact; moreover, the signaling effect is much more persistent.

Fourth, we provide novel evidence on the dynamic impact of interventions on other asset prices. We find that interest rates tend to fall in both countries, whereas the surprise depreciation has significant and heterogeneous effects on stock prices of large vs. small firms. Stock prices of the former (rather, exporters) increase, while those of the latter (rather, domestically-oriented 
firms) decrease or remain unaffected. Finally, for the Euro Area and the UK, we show that the currency depreciates significantly and persistently following exogenous interventions, as well.

Literature. Our study contributes to the literature about the effectiveness of FX interventions. One of the main challenges in this literature is the clean identification of an intervention impact in a macro environment where many forces interact. This seems easiest with high frequency data, which is where we start the short overview.

High frequency studies (e.g. Dominguez, 2003; Pasquariello, 2007; Melvin et al., 2009) can largely rule out interference by influences other than interventions due to the extremely short time interval of observation. However, their disadvantage is exactly this short-term concept. Although studies, such as Payne and Vitale (2003), use the conceptual term of a "permanent" price impact of interventions, this permanence refers to high-frequency data. They cannot say anything about the impact over many days, weeks or longer. Still, these studies provide evidence of interventions' effectiveness.

By comparison, event studies operate at lower frequencies. They typically use daily data and analyze horizons of days or a few weeks at most (e.g., Fatum and Hutchison, 2003; Fratzscher et al., 2019). Alternative approaches at this frequency include Kearns and Rigobon (2005), who exploit a policy change in Japan (and similarly in Australia), which is a countryspecific event. Thus, this method cannot be generalized. Chen et al. (2012) use a Bayesian data interpolation method to infer intra-daily intervention patterns from observable daily data as a way to improve identification. All of these approaches find that interventions are highly effective (see also Dominguez et al., 2012, 2013). However, estimates may be more affected by confounding factors than in high-frequency studies employing intra-day data.

Another alternative approach is comparison to (self-constructed) counterfactuals. A prime example is Fischer and Zurlinden (1999) who, using transactions by the Swiss central bank, find that only interventions impact exchange rates, whereas transactions as fiscal agent (which 
are transparently classified as such to the market) do not move the exchange rate. To generalize such an approach, counterfactuals can either be created by time-series forecasts (which are highly unreliable, Rossi, 2013) or by matching approaches (e.g., Fatum and Hutchison, 2003).

In relation to these approaches that rely on higher frequency data, conventional macro approaches seem to produce less reliable results. Still, there is new and innovative literature in this direction. Blanchard et al. (2015) analyze a cross-country panel with quarterly data, basically using as an instrument for FX interventions, the closeness of a country's reserves to an optimal level of reserves. Daude et al. (2016) take a similar route with monthly data, and use as instrument the ratio of reserves to M2. Finally, Adler et al. (2019) combine a set of instruments that are similar to the mentioned ones. All studies find evidence for effective FX interventions and, due to the lower frequency data, its impact seems to persist for months or longer. The problem with these approaches is the weakness of their instruments that may be plausible to some extent but tend to violate the exclusion restriction and cannot fully preclude reverse causality. Earlier papers in this direction include Dominguez and Frankel (1993), who use oral interventions as instrument for actual interventions, which would be not convincing in today's environment where communication is part of the policy concept.

The remaining paper is organized in five more sections. Section 2 describes the specific VAR model we employ. Sections 3 and 4 contain core and extended results for Japan, respectively. Section 5 documents the impact of intervention policy for the US and contains a replication of the estimation procedures for the Euro Area and the UK. Section 6 concludes.

\section{The Proxy-SVAR model}

In this section, we first discuss the specification of the reduced form model, before we outline how we construct an instrument for FX intervention shocks. Last, we show how we use the instrument to identify the structural model. 


\subsection{Reduced form model}

The VAR model is

$$
y_{t}=c+\Pi(L) y_{t-1}+\Gamma x_{t}+u_{t}
$$

and refers to variables at a daily frequency. The $k \times 1$-vector $c$ includes constant terms, the $k \times$ $l$ matrix $\Gamma$ collects the contemporaneous impact of $l$ exogenous variables contained in the vector $x_{t}$, the matrix $\Pi(L)$ in lag polynomials captures the autoregressive part of the model, and the vector $u_{t}$ contains $k$ serially uncorrelated innovations, or reduced form shocks, with $V\left(u_{t}\right)=\Sigma$ and $u_{t} \sim N(0, \Sigma)$.

We employ different specifications for the endogenous variables in $y_{t}$. The baseline specification includes the two variables that are the focus of most of the previous literature: the size of the interventions and the nominal exchange rate. Specifically, we compute the cumulative daily interventions in million US-Dollars over the full sample. We use the level of this variable as our policy indicator to scale the size of the policy shock and to estimate its persistence. Moreover, we use the log of the bilateral nominal exchange rate of the intervening country to its reference currency. We define it as foreign currency to domestic currency, such that an increase in the exchange rate implies an appreciation of the domestic currency. In extended models, $y_{t}$ includes the two baseline variables as well as additional variables, such as further bilateral exchange rates or interest rates and equity prices that change across specifications. Finally, to control for potential institutional or seasonal patterns, all models contain day-of-the-week and monthly dummies in the vector of exogenous variables.

The VAR innovations are assumed to be linearly driven by an intervention policy shock $\varepsilon_{t}^{p}$ that we aim to identify, and other structural shocks $\varepsilon_{t}^{*}$ that are of no interest for the purpose of this paper. The VAR innovations $u_{t}$ are related to the structural shocks as 


$$
u_{t}=b^{p} \varepsilon_{t}^{p}+B^{*} \varepsilon_{t}^{*}
$$

The $k \times 1$-vector $b^{p}$ captures the impulse vector to an intervention shock of size 1 and is required to generate impulse responses to a one standard deviation shock. We use the identification approach with external instruments developed by Stock and Watson (2012) and Mertens and Ravn (2013); for a textbook treatment see Kilian and Lütkepohl (2017). When a variable $s_{t}$ is available such that

$$
E\left(s_{t} \varepsilon_{t}^{p}\right) \neq 0 \text { and } E\left(s_{t} \varepsilon_{t}^{*}\right)=0
$$

it can be used to consistently estimate the impulse vector $b^{p}$. We now discuss how we compute $s_{t}$ in order to ensure that the conditions in (3) are satisfied and then outline how we use it to estimate $b^{p}$ and to identify $\varepsilon_{t}^{p}$.

\subsection{Data and instrument}

Data. We use higher frequency data (i.e. daily), as is common in the event study literature on FX interventions. The country samples depend on the data availability of the variables in $y_{t}$ and the specific FX regimes of the country under consideration. In the following, we mainly refer to the case of Japan, which publishes its daily intervention data in million USD, deferring a discussion of the data and institutional settings for the other countries to Section 5. In the bivariate models for Japan, the sample starts on April 1, 1991, when official data on interventions become available, and ends on January 4, 2017, for a total of 6,723 observations. ${ }^{1}$ In some of the extended specifications, the sample starts later, as data for one of the additional variables are not previously available. The shortest sample starts on January 2, 1995, and contains 5743 observations. Given the large number of observations, we include 50 lags of the

\footnotetext{
${ }^{1}$ We obtained data on actual interventions for the US and Japan from data repository of the Federal Reserve Bank of St. Louis, for the UK from the website of the treasury, and constructed the data on Euro intervention from Factiva news reports. Exchange rates are daily spot rates from Bloomberg (mnemonics BP0003M, EU0003M, TIO003M, and USO003M).
} 
endogenous variables, even though Akaike's information criterion indicates only between 6 and 19 lags, depending on the specification. In this way, we carefully control for secular movements in exchange rates and reliably estimate the responses of the endogenous variables at long horizons, such as 100 trading days.

For the period covered, there are 325 intervention days in Japan. They are shown over time in the upper panel of Figure 1 and summarized in Table 1. Most are purchases of USDollars. They cluster in the 1990s, but there are also interventions in the 2000s and 2010s. The average amount per intervention day is 2.2 billion US-Dollars. The Bank of Japan typically intervenes in sequences of several days or even weeks, as the difference between the unconditional and conditional intervention probability shows.

\section{$<$ Figure 1 $>$ \\ $<$ Table 1 $>$}

It is known that interventions by the Bank of Japan were conducted consistently as sterilized interventions, except during the 2010s. Sterilization is important to avoid an immediate impact on the monetary base, thus on the money market and finally on short-term interest rates, which are the instrument of monetary policy. Without sterilization, one may argue that intervention policy is accompanied by a monetary policy impulse (going into the same direction), such that identification becomes unclear. While the publicly available data we use do not necessarily represent sterilized interventions, Japan (as well as the other countries in our study) uses the short-term interest rate as its main instrument for monetary policy. Thus, the central bank has an interest in avoiding influences from FX interventions on their main instrument, so that we can safely assume (in line with some qualitative information from news reports) that there is no unintended spillover. Moreover, most FX intervention volumes are small relative to money markets and do not require immediate sterilization. Still, we later explicitly control for monetary policy actions and also see in the SVAR-estimations that FX 
interventions are not accompanied by contemporaneous interest rate changes. All this clearly indicates that we observe FX interventions that are distinct from monetary policy measures.

The procedure how decisions are made is, for example, illustrated in Ito and Yabu (2007). The central bank conducts the interventions but is not the responsible authority to make these decisions. That authority lies with the Ministry of Finance (MoF), as in other advanced economies. Receiving the permission for interventions is a costly process, which may be why they occur in sequences. Officials have to convince the top authorities, which is a discretionary process. Given this permission, follow-up interventions do not need individual consent.

Instrument. At the center of our identification strategy, we rely on the described fact that the decision to start such a sequence is usually not based on new information on the specific intervention day, but is related to medium and longer-term trends, as well as to general financial market and economic conditions. Hence, the first day of an intervention sequence can be considered as exogenous to contemporaneous exchange rates or other asset prices. By contrast, the subsequent decision after the first day of a new sequence and how long the sequence will last is taken on a day-by-day basis in response to current market conditions and the success of the initial intervention.

The largely exogenous character of the first intervention day is also apparent from intervention objectives of central banks. According to the survey of Mohanty and Berger (2013, Table 2), the objectives are to smooth the trend path, limit pressure on exchange rates, limit volatility, etc. All these are longer-term developments, so that the specific day of the intervention is not predetermined but is the discretionary decision of the responsible authority; hence the intervention is not transparent to markets, similar to the surprise component of a monetary policy decision. This becomes also clear when the policy process toward intervention is described, as it is assumed that the first intervention day is accompanied by effort to come to an intervention decision (yes or no) while later intervention days are then mainly covered by 
the first decision to intervene (e.g., Ito and Yabu, 2007). The longer-term basis for the first intervention decision is also reflected in event studies, such as Fatum and Hutchison (2003), who use averages over several days before the intervention as the basis to measure success. Finally, the most consistent empirical finding about intervention characteristics is that they "lean against the wind," i.e. interventions are based on assessing the "longer-term" development of exchange rates, clearly reaching beyond one or a few days (Sarno and Taylor, 2001; Kearns and Rigobon, 2005; Fratzscher et al., 2019).

As the first day of an intervention sequence is exogenous and, in this respect, different from other intervention days, the impact of interventions should also differ along this margin. Indeed, it is known from high-frequency studies (intra-daily data) that the first intervention contains almost all of the information and consequently moves the exchange rate while later interventions have much less impact (Zurlinden and Fischer, 1999; Payne and Vitale, 2003). We hypothesize that this pattern also holds at a daily level.

Sequences. The number of such sequences in our sample depends on the criterion used to define the start of a new sequence. We use the number of days without intervention before an intervention day to define a new sequence. Using a shorter window implies a larger number of non-zero observations for the proxy, while at the same time risks including interventions that are the continuation of an earlier sequence and, thus, potentially not fully exogenous. Therefore, we use a 5 day window, i.e. one trading week, in the construction of our baseline proxy (as used in Fatum and Hutchison, 2003, or Fratzscher et al., 2019).

This window yields 56 non-zero observations for the instrument. They are summarized in the right column of Table 1. The average intervention on the first day of a sequence is 4.8 billion US-Dollars, implying that the central bank typically intervenes more than twice as strongly on this day than on the following days of a sequence. This is in line with the idea that the decision to start a sequence is largely exogenous while the decision to intervene 
subsequently is more likely to depend on the success of the initial day. In the sensitivity analysis, we show that our results are robust to using shorter windows and thereby increasing the number of non-censored instrument observations. Furthermore, the instrument contains both purchases and sales of foreign currency. Finally, we convert them into a categorical variable, shown in the bottom part of Figure 1, containing values 1, 0, and -1 to further reduce endogeneity concerns. This transformation implies that only the decision to intervene on a particular day but not the implied volume, which could potentially depend on the success of the first transactions within that day, is considered to be exogenous.

The proxy is not required to be a correct measure of intervention shocks because several forms of measurement error can be accounted for (see Mertens and Ravn, 2013). This is important in our case as actual interventions are often accompanied by oral intervention such as communication of officials from the central bank or the Ministry of Finance (Fratzscher, 2008). The latter, however, are difficult - if not impossible - to perfectly measure as there are no official accounts of oral interventions. Moreover, central bankers discuss further features of actual interventions beyond incidence and volume, such as the instrument (for spot or derivatives see Nedeljkovic and Saborowski, 2019). Consequently, models that treat the actual interventions as the true measure of interventions are likely to underestimate the effects of interventions due to the attenuation bias resulting from measurement error. In contrast, using an instrumental variable approach requires only that $s_{t}$ correlates with $\varepsilon_{t}^{p}$ to estimate the overall effect of interventions.

\subsection{Identification of the structural VAR}

We now discuss how we use $s_{t}$ for the identification of the structural VAR. The key step consists of estimating what we will refer to as the relative impulse vector. Call $b_{i}^{p}$ the entry $i$ of the $\mathrm{k} \times 1$ impulse vector $\mathrm{b}^{\mathrm{p}}$ from equation (2). We normalize the variance of the structural 
shocks to unity, so that $b_{i}^{p}$ captures how variable $i$ responds to a one standard deviation change in $\varepsilon_{t}^{p}$. The $k \times 1$ relative impulse vector is defined as $\tilde{b}^{p}=b^{p} / b_{1}^{p}=\left(1, b_{2}^{p} / b_{1}^{p}, \ldots, b_{k}^{p} / b_{1}^{p}\right)^{\prime}$ and captures the response of the last $k-1$ variables relative to the first variable, which in our ordering is the policy indicator. $\tilde{b}^{p}$ can be estimated as $\left(1, \hat{\beta}_{2} / \hat{\beta}_{1}, \ldots, \hat{\beta}_{k} / \hat{\beta}_{1}\right)^{\prime}$, with $\hat{\beta}_{i}$ the estimated coefficients in the regressions

$$
\hat{u}_{i t}=\alpha_{i}+\beta_{i} s_{t}+v_{i t}, \quad i=1, \ldots, k,
$$

with $\hat{\mathrm{u}}_{\mathrm{it}}$ the estimated VAR residual corresponding to equation $i$ of model (1). ${ }^{2}$ The consistency of the estimate for $\tilde{b}^{p}$ follows from the fact that $E\left(u_{t} s_{t}\right)=\gamma b^{p}$ with $\gamma=\mathrm{E}\left(\mathrm{s}_{\mathrm{t}} \varepsilon_{\mathrm{t}}^{\mathrm{p}}\right)$, due to (2) and (3). As outlined in Mertens and Ravn (2013), once we have an estimate of $\tilde{b}^{p}$, we can combine it with the covariance restrictions $\Sigma=B B^{\prime}$ with $B=\left[b^{p}, B^{*}\right]$ to estimate the impulse vector $b^{p}$

We use (4) to assess the relevance of our instrument. We compute the $F$-statistic for the null hypothesis $\beta_{i}=0$, focusing on the first two equations of the VAR, i.e., those featuring the policy indicator and the USD/JPY exchange rate as dependent variable. For the bivariate model, the $F$-statistics are 509.2 and 47.9. For the extended model including interest rates and stock prices, they are 540.5 and 75.8 . These high $F$-statistics suggest that the instrument is strong.

\section{$3 \quad$ Results}

In this section, we present results for Japan. First, we show estimates for a bivariate baseline model (3.1) and an extended model containing further exchange rates to assess the effect of interventions on the currency value (3.2). Then, we extend the model by considering interest rates and stock prices (3.3). Finally, we show variance decompositions (3.4).

\footnotetext{
${ }^{2}$ An alternative approach consists of regressing $\hat{u}_{i t}$ for $\mathrm{i}=2, \ldots, \mathrm{k}$ on $\hat{\mathrm{u}}_{1 \mathrm{t}}$, instrumented with $\mathrm{s}_{\mathrm{t}}$ (Mertens and Ravn, 2013). The two procedures deliver the same estimate for $\tilde{b}^{p}$ already in a finite sample, as can be verified analytically.
} 


\subsection{Baseline model}

Figure 2 reports the impulse responses of the cumulative interventions and the USD/JPY exchange rate from the baseline bivariate VAR to an intervention shock of one standard deviation. The solid line refers to the point estimate and the shaded area to $90 \%$ confidence bands, which are based on bootstrap techniques. ${ }^{3}$ The top panel shows that a surprise intervention leads to an immediate and significant increase in the cumulated intervention series by USD 1.7 billion. The effect is highly significant and persistent. Cumulative purchases of foreign currency peak at roughly USD 2.5 billion after about 50 trading days, before slowly returning to trend.

\section{$<$ Figure $2>$}

The intervention is associated with a large and highly significant devaluation of the domestic currency. The USD/JPY exchange rate depreciates upon impact by $0.2 \%$. The impact is highly persistent as well. The exchange rate remains below the level where it would have been without the intervention shock over the full impulse horizon. Moreover, the impact is statistically significant for 250 trading days. The strong and long-lasting effects are consistent with the high persistence of the intervention. These results are qualitatively and quantitatively in line with existing evidence on the effect of FX intervention in the USD/JPY market, as we show in detail in Section 4.1. There we also highlight that our immediate impact is slightly larger than the one documented in two previous studies, which is consistent with the argument

\footnotetext{
${ }^{3}$ We apply a fixed-design wild bootstrap, as in Mertens and Ravn (2013) and Gertler and Karadi (2015). For each bootstrap we recursively generate pseudo data after randomly selecting a subset of days and then changing sign of the estimated vectors of VAR innovations on those days. For identification within each bootstrap, in correspondence to the same day, we change the sign of $s_{t}$. Within each bootstrap we then apply the procedure discussed in Section 2. Confidence bands are constructed on 200 bootstrap replications.
} 
that the Proxy-SVAR approach removes a potential attenuation bias present in models treating the actual intervention volume as the true policy shock.

Looking also at other currency markets, the result on USD/JPY is qualitatively confirmed by evidence on the DEM/USD market, where Dominguez (2003) estimates the maximum impact of a one billion US-Dollar intervention to be $0.29 \%$. In smaller (emerging) markets, however, the FX intervention impact is much larger, such as $1.8 \%$ on 100 million US-Dollar for the Australian Dollar (Kearns and Rigobon, 2005) or 0.8\% on 60 million US-Dollar for the Colombian Peso (Kuersteiner et al., 2018).

At the same time, our results reveal novel insights into the persistence of the effects. In high-frequency studies, the "permanent" effect lasts for hours (e.g., Payne and Vitale, 2003). The horizon of event studies is a little longer, although this depends on the exact success criterion chosen. If we refer, for example, to Fatum and Hutchison (2003), their direction criterion measures the impact during a post-intervention period of 2 to 15 days. In robustness exercises, they extend this period up to 30 days and find that the intervention effect becomes insignificant. There are only a few macro-oriented studies, including Blanchard et al. (2015), Daude et al. (2016), and Adler et al. (2019), considering effects over several months. However, their approach differs from ours in three respects: first, they mainly cover emerging markets and, thus, predominantly not floating exchange rates; second, their measure of FX intervention is necessarily quite imprecise as they cannot rely on true intervention data but proxies derived from changes in official reserves; and, third, while their IV-estimation is innovative in the field, the specific assumptions are at the same time debatable. Overall, according to our knowledge, the implementation of a well identified structural VAR is new to the literature on FX intervention. Thus, our empirical result of a "persistent" effect (lasting several months and up to quarters) has a previously unmet level of credibility. 


\subsection{Effects on further exchange rates}

While focusing on the direct impact of a Japanese intervention on the USD/JPY exchange rate, we extend this bivariate model also to two other important exchange rates relative to the Yen, i.e. the Euro (EUR/JPY) and the British Pound (GBP/JPY). It is expected that the intervention in the USD-JPY market, intended to weaken the Yen, will impact the two other exchange rates into the same direction due to the interrelations on foreign exchange markets. Results are shown in Figure 3.

$<$ Figure 3 $>$

The graphs on cumulated interventions and their impact on the USD/JPY remain largely the same, although the impact on the exchange rates is slightly weaker. The impacts on EUR/JPY and GBP/JPY mirror qualitatively those of the targeted US-Dollar. The initial effects are similar for all three currencies. The most relevant difference compared to the bivariate model is that the impact on the EUR/JPY turns insignificant after about 30 to 40 trading days; this may be partially caused by the fact that the USD/EUR rate is the most important exchange rate and dominates any impacts from the Yen and respective interventions. Overall, these results support the impression of a significant impact of FX intervention on exchange rates.

\subsection{Effects on interest rates and stock prices}

The two models presented so far provide a first impression of interventions on exchange rates. We next extend the bivariate model, presented in Section 3.1, by also considering four interest rates and two stock market indices, i.e. large and small firms listed on the Tokyo Stock Exchange. ${ }^{4}$ Specifically, to capture the differential stances of monetary policy, we consider the

\footnotetext{
${ }^{4}$ We use the MSCI Japan Large (Small) Cap Index, which contains 139 (979) constituents and covers approximately $70 \%$ (14\%) and of the free float-adjusted market capitalization in Japan. We obtained both series from Bloomberg (mnemonics MXjplc index and MXjpsc index, respectively). The mnemonics for yield data from Bloomberg are GJGB3M Index, GJGB1 Index, GJGB2 Index, GJGB5 Index, and GJGB10 Index.
} 
short-term (three months) interest rate differential between Japan and the US. In addition, we consider the 2-year, 5-year and 10-year risk-free interest rates in Japan.

The additional variables serve two purposes. First, we are interested in the asset market effects of FX intervention shocks per se, as these have received only scant attention in the literature. Movements in interest rates in response to the intervention shocks can give indications about changing expectations about inflation or future monetary policy of market participations and stock prices may approximate risk appetite and future real growth of the domestic economy.

Second, a large model addresses potential concerns about omitted variables in the smaller models. To see whether the augmented structural VAR model is invertible, we follow Stock and Watson (2018) and test the null hypothesis that lags of the instrument are jointly equal to zero in each of the VAR equations. We consider up to six lags. Table 2 indicates that there is no statistically significant evidence against the hypothesis of invertibility. This finding is consistent with the notion that exchange rates, interest rates, and equity prices summarize a potentially large set of information such that there are no omitted factors.

$<$ Table 2>

Figure 4 shows that the impact of FX intervention shocks on the USD/JPY in the larger model is qualitatively and quantitatively similar to the effects in the smaller models. Moreover, it reveals that the responses of interest rates tend to be first negative, but that they are often only marginally statistically significant. For the short-term interest rate differential, it is comforting that there is no instantaneous impact; this confirms that we indeed observe a FX intervention shock and not contemporaneous monetary policy effects. To reduce the risk of confounding monetary policy shocks further, we check for all 56 days with non-censored proxy observation whether there was a concurrent monetary policy event. We find only two such overlaps (March 8, 2000 and August 4, 2011) and excluding them leaves the results virtually unchanged. 
$<$ Figure $4>$

Turning to the longer-term interest rates, their reaction follows a similar pattern, being mostly insignificant except for a significant decrease of the two-year rate (by 0.1 basis points) for the first 10 to 20 days. Otherwise, interest rates tend to fall by about 0.1 to 0.2 basis points during the first 20 days and from thereon they tend to rise for another 20 days, overshoot the starting level by about 0.1 to 0.2 basis points and then move toward the level before the shock. An explanation might be that monetary policy tends to slightly support the interventionintended weakening of the Yen by rather loosening than tightening. While this may shortly spillover to the longer-term rates, potential effects of a Yen depreciation on inflation and growth would induce higher interest rates before the overall limited effects level off.

The situation is different for stock prices. A depreciation of the Yen improves the competitiveness of exports and may allow firms to increase associated profits. FX intervention can however affect firms differently, depending on how export-oriented and competitive they are (for a model, see Verhoogen 2008). Empirically, we find that large firms' stock prices are immediately positively impacted by the intervention shock. They rise significantly by about $0.1 \%$ for 10 days and keep their level thereafter. The depreciation increases the competitiveness of exports, which are more important for larger and more internationally oriented firms and, thus, supports their business. By contrast, the impact of the shock on the stock prices of small firms is negative by about $0.1 \%$ for 10 days, before stock prices return to the pre-shock level. The negative effect seems reasonable, as this more domestically-oriented segment of the economy profits less from the depreciation boosting exports, while at the same time incurring higher import costs.

\subsection{Variance and historical decomposition}


To quantify the average economic importance of FX interventions for exchange rate and other asset price fluctuations, Table 3 documents the contribution of the estimated intervention shocks to the forecast error variance of the respective time-series at various horizons.

Turning to cumulated interventions, the high explained variance is a rather mechanical effect as intervention shocks are the main driving force. Turning to asset prices, the largest effect is observed on the USD/JPY exchange rate. Here the explained variance starts at a remarkable $11.5 \%$ and decreases to $5.2 \%$ for longer horizons. This indicates that intervention shocks are relevant for understanding the USD/JPY exchange rate (although its influence on the exchange rate is not dominating). By contrast all 20 effects on interest rates - regarding the four measures and five horizons - remain below $0.4 \%$ are thus rather negligible. Finally, the explained variance of stock prices is larger than that of interest rates but still small. The share of explained variance is larger for large firms than for small firms, and is between $0.5 \%$ and $0.7 \%$ over the horizons covered.

$<$ Table 3>

To assess the economic importance of intervention shocks during certain times in our sample, we compute a historical decomposition of the exchange rate. The top panel of Figure 5 shows that the contribution of intervention shocks to the bilateral USD/JPY exchange rate is limited throughout most of the sample. There are, however, two noteworthy episodes where interventions curbed the appreciation of the Yen: in 2003/04 when purchases of USD reached hitherto unseen frequency and levels under the newly appointed Director General of the MoF's International Bureau Hiroshi Watanabe, and in 2011 following the massive Tohoku earthquake and the ensuing Tsunami hitting Japan's coast. This is reflected in the estimated intervention shocks in the bottom panel, which suggest that Japanese authorities massively purchased foreign currency during these episodes to stem the appreciation of the domestic currency, consistent with the implicit aim of smoothing the exchange rate. 
$<$ Figure $5>$

\section{$4 \quad$ Results in perspective}

In this section, we put our main results in perspective. First, we compare them with those of earlier papers by adjusting the sample period (4.1). Second, we compare our identification strategy to an alternative identification scheme (4.2); third, we provide evidence on the working and relative importance of transmission channels of FX interventions (4.3); fourth, we run robustness checks by using modified versions of the instrument addressing concerns that it is predictable (4.4); and, fifth, we provide a range of sensitivity analyses (4.5). Due to space constraints, Sections 4.4 and 4.5 only report major results while the appendix contains all details.

\subsection{Comparison with the literature}

In order to more exactly compare the intervention impact with those measured in other studies about USD/JPY interventions, we use the model from Section 3.1, adjusting the observed sample period to align more closely to those of Kearns and Rigobon (2005) and Chen et al. (2012). In particular, we let the sample end in 2010, which removes the few huge interventions from 2011. In this way, we also assess the suitability of the assumption that the start of an intervention sequence is exogenous to the current economic environment. This condition is more likely to hold when the central bank is in the market frequently (as in the earlier part of the sample) than when it is intervening rarely, in which case FX policy is more likely prompted by something concurrent. Moreover, we adjust the shock size to one trillion Yen as in the mentioned papers.

Figure 6 contains the results. Relative to the full period 1991-2017 (thick solid line with confidence bands), the intervention impact nearly doubles. It increases from about $1.2 \%$ to 
nearly $2 \%$ (dotted line). This impact is larger than the comparable impacts estimated by Kearns and Rigobon (1.49\%) and Chen et al. (1.8\%). As, for example, Kearns and Rigobon (2005) emphasize the policy change in June 1995, we also test whether a start of the analysis after this point in time has a major influence on our results. This is not the case, as can be seen from the dashed lines, and the immediate impact is the same as for our longer sample. Next, we combine both modifications of the sample and test whether a later start (in 1995) and an earlier end (in 2010) jointly affects the estimates. The dash-dotted line shows that the results are similar to those if we exclude only the later part of the sample. Finally, we shorten the sample further to investigate whether the policy change in 2004 toward fewer but larger interventions affects our results by ending the sample in 2004. Again, the impact in the shorter sample is larger than for the full sample (see thin solid line).

$<$ Figure 6 $>$

\subsection{Comparison to identification via timing restriction}

So far, the literature based on daily data usually relates some measure of the exchange rate to intervention volume. Often, there is the additional assumption that the latter is exogenous. In a dynamic setting, this amounts to a Cholesky decomposition of the reduced form covariance matrix of a model with the cumulated intervention sequence ordered first. Such a model means that FX interventions are assumed to contemporaneously impact the exchange rate and the other asset prices in the model, but not the other way round, and that the actual intervention volume correctly measures the intervention shock.

Instead, if our argument holds that only the first day of an intervention sequence can be considered as exogenous and that intervention often contains elements of communication as well, we would expect that the Proxy-SVAR produces larger and more precise estimates of the efficacy of interventions. First, it does not consider subsequent interventions within a sequence 
as exogenous, which might introduce a bias toward zero in the estimates if the central bank leans against the wind on a day-by-day basis. Second, it accounts for measurement error and does not treat the actual interventions as a one-to-one mapping to the structural shocks, thereby reducing a potential attenuation bias.

Figure 7 presents the estimates from a Cholesky ordering of the variables, and our modeling approach (from Section 3.3). It shows that the Proxy-SVAR leads to larger impacts of FX intervention shocks. Regarding the exchange rate, the effect is twice as large and lasts for 100 days, whereas for the recursive model it is indistinguishable from zero after only 10 days. Interest rates show the same pattern as before, but effects are even smaller and consistently insignificant under the timing restriction. Regarding stock prices, there is no longer an effect on large firms and only a short-lived effect (5 days) on small firms' stock prices. Thus, it may be reassuring that a different method leads to the same qualitative findings but if one is convinced by the superiority of the Proxy-SVAR, this method is crucial to obtain relatively large and persistent effects on exchange rates and stock prices.

$<$ Figure 7 $>$

\subsection{Transmission channels of FX interventions}

The literature dealing with the mechanisms by which FX interventions may impact exchange rates is dominated by two channels, the portfolio (balance) channel and the signaling channel (Sarno and Taylor, 2001). According to the portfolio channel, the intervention changes supply and demand for the respective currencies in the market, thus impacting the price, i.e. the exchange rate. According to the signaling channel, the intervention communicates further information than just the sale or purchase of foreign currency, which also impacts the exchange rate. The portfolio channel is seen with increasing skepticism with respect to advanced markets due to their huge transaction volumes relative to the limited intervention amounts. The signaling 
channel has also met skepticism because it is not obvious what "further information" could be signaled. If this information was about monetary policy, then the intervention would rather be a communication tool for monetary policy than an independent instrument.

As the empirical validity of these channels is not fully clear-cut, the following two analyses aim to disentangle the portfolio channel from the signaling channel. First, we compare the Proxy-SVAR-approach, which intends to capture all transmission channels, to a Cholesky ordering approach, as introduced above. As the latter basically relies on intervention volumes, the difference can be interpreted economically as being an approximation for the pure contribution from communication; or in the language of transmission channels, the ProxySVAR captures all channels, i.e. portfolio and signaling, while the Cholesky approach captures the portfolio channel only, such that the difference informs about the signaling channel. The second analysis, in order to identify transmission channels, addresses the issue of communication directly. Somewhat simplifying, we argue that by using communication around interventions, central banks clearly aim for a signaling channel. Thus interventions without any communication may be secret but do not need to be; in any case, these interventions work through the portfolio channel but hardly exploit the signaling channel.

The difference between a Proxy SVAR and a Cholesky approach. We compare a model identified with a Cholesky decomposition to a Proxy-SVAR using our baseline instrument. In order to make both approaches as comparable as possible, we include the cumulated intervention volume on each first day of a sequence as our policy indicator. This is different from Section 4.2 (Figure 4), which uses the cumulative volume of all interventions, including the volume on subsequent intervention days. The latter days entail the risk of containing endogenous responses to current market conditions, that is, to the success of the initial intervention. The Cholesky decomposition implies that we assume that the intervention volume at the first day of a sequence is exogenous and a one-to-one mapping to the intervention 
shock. This is meant to approximate the impact of the portfolio channel. Instead, the ProxySVAR allows for measurement error and an interpretation of this error, i.e. the difference between the actual intervention and the estimated latent shock, is the potential impact of communication. Hence, the difference between both approaches captures the signaling channel.

Results in Figure 8 show that the qualitative patterns remain the same as shown in Figure 4 for our baseline Proxy-SVAR and in Figure 7 for the comparison between our baseline ProxySVAR and a standard recursive identification approach. Figure 8 suggests that the transmission of intervention shocks functions through both channels. For the purpose of comparison, we scale the shock in both cases to one billion USD. We conclude, following the suggested interpretation, that the portfolio channel accounts for about one-third of the overall effect. However, at about ten trading days, the impact is relatively short-lived. The signaling channel accounts for the remaining two-thirds of the overall effect and is much more persistent (for more than 100 trading days).

\section{$<$ Figure $8>$}

The difference between interventions with and without communication. In order to conduct the comparison between portfolio and signaling channels with a second approach, we need data about communication in the markets that is related to FX interventions. To this end, we create a database consisting of daily news items on Bloomberg and Factiva that cover foreign exchange intervention by central banks in our sample. To identify relevant news items, we designed a structured query involving terms such as "foreign exchange," "fx," and "intervention". 5 Based on each intervention day in our actual intervention data, we define a

\footnotetext{
${ }^{5}$ The Factiva query is structured as follows: (foreign exchange or fx or forex or currenc*) and (intervene* or operation?) and (countrystub near10 interven*) and (rst=trtw or $r s t=t$ prw or $r s t=t d j w)$ and (central bank or ministry of finance or treasury ministry or monetary authority)", where countrystub is, for example, Japan*. Other settings: language=English, Region=respective country, all dates, all sources, all authors, etc. On Bloomberg, which has less advanced search settings, we connect "foreign exchange" and country name with AND and the other parts of the Factiva query using OR.
} 
sampling period using a window of $+/-3$ days around each intervention. Within these windows, we consider all news items that are yielded by the structured query. Overall, these raw data consist of thousands of news items.

To weed out news that are irrelevant to our research question, such as information about interventions in other countries or news about other policy interventions, we manually code each news item from the relevant time period following a systematic coding scheme. The core issue of interest to us is whether the market knew about an intervention. This can be the case if the central bank confirms an intervention or if it backs actual intervention up with oral intervention (e.g. making a statement like: "We are concerned about the dollar exchange rate and will intervene to avoid further appreciation of the yen.”). Additionally, rumors reported by relevant players, such as statements by traders that the central bank was intervening in the market, are clear signs that market participants know about interventions taking place. Therefore, we also code these cases as days when intervention activity is known about. In addition, we coded whether the market was anticipating intervention. A respective statement would be: "Traders are worried about possible future BOJ intervention to strengthen dollar." The result of the coding effort is a time series that specifies for each day whether market participants knew about or expected an intervention taking place on that day. If the first intervention day of any intervention episode falls on such a day, then this is considered a FX intervention with communication. Of these, we have 12 cases in the sample; 29 cases are without communication. ${ }^{6}$

This is the necessary ingredient for our second approach, which aims at explicitly capturing the measurement error by considering communication. Thus, we compare two versions of a Proxy-SVAR using alternative subsets of non-censored instrument observations. The first set contains 29 days where we observe actual interventions without communication

\footnotetext{
${ }^{6}$ The number is reduced from 56 to 41 because some early-year-data for the extended model are not available.
} 
such that the identified shock will approximate the portfolio channel. The second set contains 12 days where actual interventions are accompanied by communication meaning that the identified shock captures both channels. Hence, the difference between the first and the second shock can be interpreted as the signaling channel. We need to assume, however, that both timeseries are otherwise the same, implying that the use of communication is not dependent on specific circumstances. To back this assumption, we use the actual intervention volume on each first day of an intervention sequence, instead of the intervention direction used in the baseline model. In this way, we account for the potentially differing average volumes between the instrument sets.

Results are shown in Figure 9. Reassuringly, the qualitative pattern of impulse responses resembles the earlier aggregate results. There is a remarkable difference, however, in the impact size between FX interventions with and without communication: the former seem to be about three times as strong as the latter, indicating - if one follows our arguments - that the signaling channel is twice as powerful as the portfolio channel. This confirms the results of our earlier approach in this section that were shown in Figure 8 from another perspective.

$$
<\text { Figure } 9>
$$

\subsection{Robustness checks}

In this section, we perform four analyses to see how the results are affected. First, we use a policy reaction function approach to clean the instrument. Second, we redefine intervention sequences using a stricter criterion. Third, we exclude coordinated interventions and, fourth, we perform a counterfactual analysis by purposely applying a "useless" instrument variable in our Proxy-SVAR approach, i.e. the second day of an intervention episode (instead of the first day). The results in all cases support the robustness of our findings documented above. Details are documented in Appendix A. 


\subsection{Further sensitivity analyses}

In this section, we summarize the results from extensive sensitivity analyses. They demonstrate that our main results are robust. In detail, we exclude either the weekday or month dummies from the set of exogenous variables, or include either a linear trend or year dummies. Furthermore, we use different numbers of lags of the endogenous variables. Then we modify the definition of an intervention sequence, we use intervention size instead of the categorical variable, we use shortened sample periods, and finally we apply an alternative bootstrap methodology, proposed by Jentsch and Lunsford (2019). Full results are shown in Appendix B.

\section{Evidence for the US, Euro Area, and UK}

After showing that the identification and estimation methodology works well and produces reasonable estimates for Japan, we turn to an analysis of the US, Euro Area, and the UK, both for their own sake and as tests of the external validity to alleviate concerns that the above results may be driven by unknown specifics of the Japanese case. All three countries have had floating exchange rates throughout the sample period, and results qualitatively support the analysis for Japan. For the sake of brevity, the analyses of the Euro Area and the UK, where we have much less data than for Japan and the US, are shown in Appendix C.

In the US, the Treasury has the legal responsibility for FX interventions, as in Japan. It closely cooperates with the Federal Reserve. On behalf of both, the Federal Reserve Bank of New York conducts the market operations, which it sterilizes. Interventions were relatively frequent until the early 1990s. Subsequently, they are less frequent, while after 1995 there are only a few, albeit important, cases. For comparability, we use the same sample, extended model specification, and lag length as for Japan. For the period before the introduction of the Euro, 
we use the Deutsche Mark/USD exchange rate as reference cross-rate and the German shortterm rate to compute the interest rate differential. ${ }^{7}$

Table 4 contains summary statistics for US interventions. There are 38 actual interventions in the sample - most are sales of the foreign currency, typically Deutsche Mark/ Euro or Yen - such that the unconditional intervention probability on a given day is below $1 \%$. As for Japan, the conditional probability is substantially larger, implying that in the US there is also a tendency to intervene in sequences, although they are on average shorter. The average daily volume as well as the maximum daily purchase and sale are smaller as well - at USD $0.38,1.31$ and 1.60 billion, respectively.

$<$ Table 4>

The right column in Table 4 shows that we have 25 non-censored observations for the instrument, including both purchases and sales of foreign currency and the maxima of each. We construct it analogously to the case of Japan, that is, we use only starts of sequences, which are defined as having at least five preceding days without intervention. The instrument is strong. The $F$-statistic is 3842.3 and 16.7 , when testing its relevance for instrumenting the residuals of the cumulated intervention equation and the exchange rate equation, respectively, in the extended eight-variable model. To ensure that it is uncorrelated with US monetary policy shocks, we compare all 25 days with the dates of Federal Open Market Committee (FOMC) meetings. There is no overlap.

Figure 10 contains the dynamic effects of an intervention shock of one standard deviation. This corresponds to an initial purchase of foreign currency of about USD 50 million and, on average, a few additional purchases over subsequent days. The US-Dollar depreciates

\footnotetext{
${ }^{7}$ To measure stock prices of large (small) companies we use the Dow Jones Industrial Average 30 Index and the Russel 2000 Index, respectively. We obtain all financial data for the US model, including interest rates, from Bloomberg. The mnemonics are: DJITR Index, RU20INTR Index, USGG3M Index, USGG2YR Index, USGG5YR Index, and USGG10YR Index.
} 
immediately by roughly 5 basis points. The effect is statistically significant at the $90 \%$ level. The currency remains significantly below trend for about 40 trading days. Then, it gradually returns to the level where it would have been without the surprise intervention and from which it cannot be distinguished statistically two months after the shock.

$<$ Figure 10>

The interest rate differential does not respond upon impact. This indicates that there is no confounding US monetary policy shock, which is consistent with our earlier assertion that none of the 25 non-censored instrument observations coincides with a FOMC meeting. From the second day after the exogenous intervention onwards, however, the interest differential declines significantly and persistently, potentially reflecting a more accommodative stance of the Federal Reserve. In line with the drop in the short-term rate, longer-term interest rates drop significantly as well; by roughly half of a basis point after 5 days. The impact dies out after about 10 days. The value of firms increase, but only the impact effect for large companies is statistically significant.

Qualitatively, the estimates for the US are similar to those for Japan. Our results indicate, for a purchase of foreign currency, a significant depreciation of the domestic currency, a tendency for interest rates to fall, and a tendency for stock prices to increase - in particular those of larger companies. This is reassuring as it suggests that our earlier estimates reveal a more general pattern of the asset market effects of surprise FX interventions, which can be an effective tool for stabilizing the exchange rate.

However, there are also some interesting differences between the countries. Consistent with the raw data, which show that the US typically intervenes with smaller volumes (see Table 4), a one standard deviation shock in the US is substantially smaller in terms of US-Dollars than in Japan. Moreover, while there is a tendency in both countries to intervene in sequences, the intervention response in the US is less hump-shaped, peaking earlier. In line with the lower 
volume of cumulative sales of USD for a given initial intervention, the depreciation is more short-lived and less statistically significant than in Japan. Table 5 shows that interventions also play a smaller role for fluctuations of the exchange rate in the US. They explain an average of between $1 \%$ and $2 \%$ of the forecast error variance, depending on the horizon. They have essentially no explanatory power for longer-term interest rates and stock prices, but contribute up to $5 \%$ to the variability of the interest rate differential.

$<$ Table 5 $>$

At the same time, interventions are more effective in the US. An unexpected initial purchase of foreign currency worth USD 1 billion has an impact effect of $0.85 \%$ on the exchange rate. In Japan, a shock of the same size implies an impact effect of $0.13 \%$. One potential explanation for this difference is that the signaling channel, whereby interventions signal the future stance of policy, is more powerful during the sample period in the US. In particular, there is only one non-censored proxy observation (March 18, 2011) for the US during the period when the federal funds rate was at the zero lower bound. In sharp contrast, about half (27) of the non-censored proxy-observations for Japan coincide with periods when the shortterm rate was below $0.5 \%$. As Japanese policy rates already fell to zero in the early 2000 s and attempts to pursue unconventional monetary policies faltered, the effectiveness of monetary policy - and thus part of the signaling channel - was essentially clogged during a large part of the sample. In contrast, this seems to have been less of a constraint on the effectiveness of FX interventions in the US.

This interpretation aligns with the significant and persistent drop of the short-term interest rate differential in the US, which falls by about 30 basis points two months after an intervention shock of USD 1 billion. For a same-sized shock, the differential barely moves in Japan, falling by less than half of a basis point, and the response is essentially indistinguishable from zero. It is also in line with the larger explanatory power of intervention shocks for US short-term 
interest rate differentials, where they explain up to $5 \%$. In Japan, they contribute less than half of a percent to the variance of that variable.

\section{Conclusions}

FX intervention is, in many respects, a macro issue. Despite being a common method in other areas of macroeconomic research, such as examining the impact of monetary policy, the literature on FX interventions hesitates to apply VAR-approaches. The empirical problem is the partial endogeneity of FX interventions and the difficulty of measuring them precisely, as they are multi-dimensional policy actions. So, how can we properly identify FX interventions and still obtain results that fit into macro-oriented research?

While some macro-oriented papers make major assumptions for identification, we remain closer to the convention of working with higher frequency data and apply an approach that is new to the field of FX intervention: the external instrument VAR that combines a regular VAR with an event study identification strategy. The identifying assumption is based on the fact that FX interventions typically occur in sequences. Each first FX intervention then differs from subsequent ones because the first intervention is typically not driven by events on the specific day but by exchange rate developments over a longer period; in particular, in floating exchange rate regimes. This assumption is well documented in the intervention objectives of central banks and reflected in the empirical literature.

With this identification strategy, we set up the Proxy-SVAR, which has three appealing consequences: first, this method provides a more precise estimate of the impact of intervention shocks than conventional SVARs or other time-series techniques that do not account for measurement error; second, by way of the SVAR we can better assess the persistence of the effects than in event studies; and, third, by extending the SVAR to further asset prices beyond exchange rates we obtain a fuller picture of its broader impact. 
We apply this approach focusing on Japanese and US data because both countries have a flexible exchange rate, are relevant markets, and there are many publicly known FX interventions. Our main findings are fourfold: (i) interventions have a sizable impact on the exchange rate. For Japan, a 1.7 billion US-Dollar intervention has a contemporaneous impact on the USD/JPY of $0.2 \%$. This shock is of similar size but somewhat higher than many previous estimates, fitting the expectation that the method we employ reduces the attenuation bias. For the US, the impact of intervention shocks is larger. (ii) The impact on the exchange rate remains significant for several months. (iii) Disentangling the intervention impact to channels, our evidence indicates that the signaling channel dominates the portfolio channel by a ratio of two to one and by being much more persistent. (iv) Interest rates tend to fall in response to the intervention shock, whereas stock prices of larger firms rise. Robustness checks show that these main findings hold in various settings and extensions. Moreover, applying the approach to a small set of Euro Area and UK FX interventions confirms their effectiveness for exchange rate stabilization.

\section{References}

Adler, Gustavo, Noemie Lisack and Rui C. Mano. 2019. Unveiling the Effects of FX Intervention: A Panel Approach. Emerging Markets Review, 40, Article 100620.

Basu, Suman S., Atish R. Ghosh, Jonathan D. Ostry and Pablo Winant. 2018. Managing Capital Outflows with Limited Reserves. IMF Economic Review, 66(2), 333-374.

Blanchard, Olivier, Gustavo Adler and Irineude Carvalho Filho. 2015. Can FX Intervention Stem Exchange Rate Pressures from Global Capital Flow Shocks? NBER WP No. 21427. Cavallino, Paolo. 2019. Capital Flows and Foreign Exchange Intervention. American Economic Journal: Macroeconomics, 11(2), 127-170. 
Chang, Roberto. 2018. Foreign Exchange Intervention Redux. NBER WP No. 24463.

Chen, Chih-Nan, Tsutomu Watanabe and Tomoyoshi Yabu. 2012. A New Method for Identifying the Effects of Foreign Exchange Interventions. Journal of Money, Credit and Banking, 44(8), 1508-1533.

Daude, Christian, Eduardo Levy Yeyati and Arne Nagengast. 2016. On the Effectiveness of Exchange Rate Intervention in Emerging Markets. Journal of International Money and Finance, 64, 239-261.

Dominguez, Kathryn M.E. 2003. The Market Microstructure of Central Bank Intervention. Journal of International Economics, 59, 25-45.

Dominguez, Kathryn M.E., Rasmus Fatum and Pavel Vacek. 2013. Do Sales of FX Reserves Lead to Currency Appreciation? Journal of Money, Credit and Banking, 45(5), 867-890.

Dominguez, Kathryn M.E. and Jeffrey A. Frankel. 1993. Does FX Intervention Matter? The Portfolio Effect. American Economic Review, 83(5), 1356-1369.

Dominguez, Kathryn M.E., Yuko Hashimoto and Takatoshi Ito. 2012. International Reserves and the Global Financial Crisis. Journal of International Economics, 88, 388-406.

Fanelli, Sebastian and Ludwig Straub. 2017. A Theory of Foreign Exchange Interventions. Working Paper, MIT.

Fatum, Rasmus and Michael M. Hutchison. 2003. Is Sterilized FX Intervention Effective after All? An Event Study Approach. Economic Journal, 113(487), 390-411.

Fischer, Andreas M. and Mathias Zurlinden. 1999. Exchange Rate Effects of Central Bank Interventions: An Analysis of Transaction Prices. Economic Journal, 109(459), 662-676.

Frankel, Jeffrey. 2016. The Plaza Accord, 30 Years Later, in: C.F. Bergsten and R. Green (eds.), Currency Policy Then and Now: 30th Anniversary of the Plaza Accord. Peterson Institute for International Economics: Washington. 
Frankel, Jeffrey. 2019. Systematic Managed Floating. Open Economies Review, 30(2), 255295.

Fratzscher, Marcel. 2008. Oral Interventions versus Actual Interventions in FX Markets - An Event-Study Approach. Economic Journal, 118(530), 1079-1106.

Fratzscher, Marcel, Oliver Gloede, Lukas Menkhoff, Lucio Sarno and Tobias Stöhr. 2019. When Is Foreign Exchange Intervention Effective? Evidence from 33 Countries. American Economic Journal: Macroeconomics, 11(1), 132-156.

Gabaix, Xavier and Matteo Maggiori. 2015. International Liquidity and Exchange Rate Dynamics. Quarterly Journal of Economics, 130(3), 1369-1420.

Gertler, Mark and Peter Karadi. 2015. Monetary Policy Surprises, Credit Costs, and Economic Activity. American Economic Journal: Macroeconomics, 7(1), 44-76.

Ghosh, Atish R., Jonathan D. Ostry and Mahvash S. Qureshi. 2017. Managing the Tide: How Do Emerging Markets Respond to Capital Flows? IMF Working Paper 17/69.

Hassan, Tarek A., Thomas M. Mertens and Tony Zhang. 2016. Currency Manipulation. NBER WP No. 22790.

Ilzetzki, Ethan, Carmen M. Reinhart and Kenneth S. Rogoff. 2019. Exchange Arrangements Entering the 21st Century: Which Anchor Will Hold? Quarterly Journal of Economics, 134(2), 599-646.

International Monetary Fund (IMF). 2012. The Liberalization and Management of Capital Flows: An Institutional View. International Monetary Fund, Washington, D.C.

Ito, Takatoshi and Tomoyoshi Yabu. 2007. What Prompts Japan to Intervene in the Forex Market? A New Approach to a Reaction Function. Journal of International Money and Finance, 26(2), 193-212. 
Jentsch, Carsten and Kurt Lunsford. 2019. The Dynamic Effects of Personal and Corporate Income Tax Changes in the United States: Comment. American Economic Review, forthcoming.

Kearns, Jonathan and Roberto Rigobon. 2005. Identifying the Efficacy of Central Bank Interventions: Evidence from Australia and Japan. Journal of International Economics, 66(1), 31-48.

Kilian, Lutz and Helmut Lütkepohl. 2017. Structural Vector Autoregressive Analysis. Cambridge University Press.

Kuersteiner, Guido M., David C. Phillips and Mauricio Villamizar-Villegas. 2018. Effective Sterilized Foreign Exchange Intervention? Evidence from a Rule-Based Policy. Journal of International Economics, 113, 118-138.

Melvin, Michael, Lukas Menkhoff and Maik Schmeling. 2009. Exchange Rate Management in Emerging Economies: Intervention via an Electronic Limit Order Book. Journal of International Economics, 79(1), 54-63.

Mertens, Karel and Morten O. Ravn. 2013. The Dynamic Effects of Personal and Corporate Income Tax Changes in the United States. American Economic Review, 103(4), 12121247.

Mohanty, Madhusudan S. and Bat-el Berger. 2013. Central Bank Views on FX Intervention. in: Bank for International Settlements, Market Volatility and FX Interventions in EMEs: What has Changed? BIS Paper No.73, Basel, 55-74.

Nedeljkovic, Milan and Christian Saborowski. 2019. The Relative Effectiveness of Spot and Derivatives-Based Intervention. Journal of Money, Credit and Banking, 51(6), 14551490.

Neely, Christopher J. 2008. Central Bank Authorities' Beliefs about FX Intervention. Journal of International Money and Finance, 27(1), 1-25. 
Obstfeld, Maurice, Jonathan D. Ostry and Mahvash S. Qureshi. 2019. A Tie That Binds: Revisiting the Trilemma in Emerging Market Economies. Review of Economics and Statistics, 101(2), 279-293.

Pasquariello, Paolo. 2007. Informative Trading or just Costly Noise? An Analysis of Central Bank Interventions. Journal of Financial Markets, 10(2), 107-143.

Payne, Richard and Paolo Vitale. 2003. A Transaction Level Study of the Effects of Central Bank Intervention on Exchange Rates. Journal of International Economics, 61(2), 331352.

Rossi, Barbara. 2013. Exchange Rate Predictability. Journal of Economic Literature, 51(4), 1063-1119.

Sarno, Lucio and Mark P. Taylor. 2001. Official Intervention in the FX Markets: Is It Effective and, If So, How Does It Work? Journal of Economic Literature, 34(3), 839-868.

Stock, James H. and Mark W. Watson. 2012. Disentangling the Channels of the 2007-2009 Recession. Brookings Papers on Economic Activity, Spring, 81-135.

Stock, James H. and Mark W. Watson. 2018. Identification and Estimation of Dynamic Causal Effects in Macroeconomics Using External Instruments, Economic Journal, 128(610): 917-948.

Verhoogen, Eric A. 2008. Trade, Quality Upgrading, and Wage Inequality in the Mexican Manufacturing Sector, Quarterly Journal of Economics, 123(2), 489-530.

Vitale, Paolo. 2003. Foreign Exchange Intervention: How to Signal Policy Objectives and Stabilise the Economy. Journal of Monetary Economics, 50, 841-870. 


\section{Figure 1: Interventions and instrument}

The figure shows the actual FX interventions by of the Bank of Japan. The top panel contains all 325 interventions in the sample. The bottom panel shows the 56 starts of an intervention sequence as categorical variable, which we use as an instrumental for the identification of latent intervention shocks.
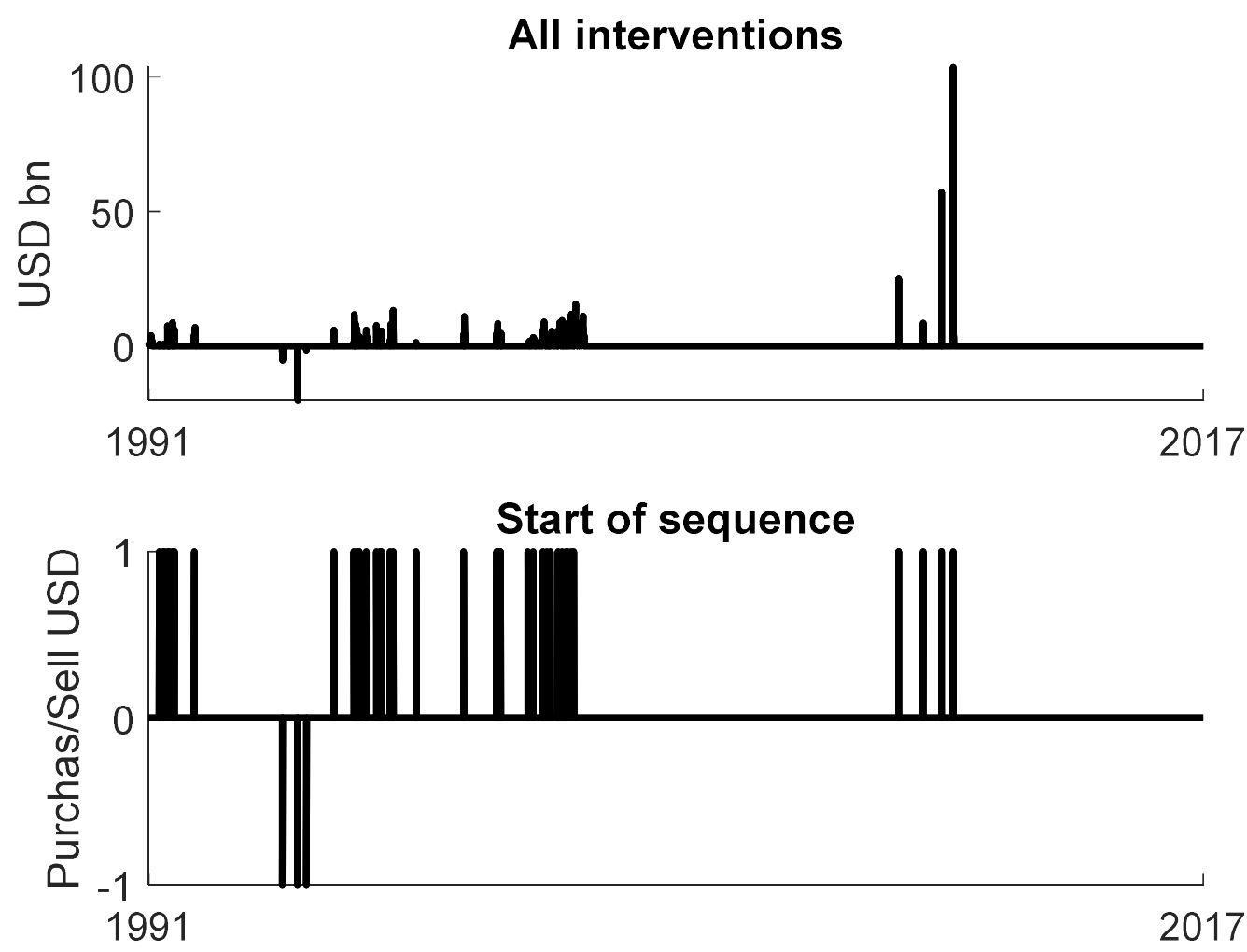

Table 1: Descriptive statistics for Japan

\begin{tabular}{lcc}
\hline & All interventions & $1^{\text {st }}$ day of sequence \\
\hline Number of interventions & 325 & \\
Number of interventions & 319 & 56 \\
Purchases of foreign currency & 6 & 53 \\
Sales of foreign currency & 0.05 & 3 \\
Unconditional probability & 0.65 & 0.01 \\
Conditional on previous intervention & & 0 \\
& & \\
In billion USD & 2.16 & 4.79 \\
Average intervention & 2.30 & 5.16 \\
Average purchase & -5.29 & -1.80 \\
Average sale & 0.80 & 1.21 \\
Median intervention & 103.53 & 103.53 \\
Maximum purchase & -20.32 & -2.21 \\
Maximum sale & & \\
\hline
\end{tabular}


Figure 2: The dynamic effects of FX intervention shocks in Japan

The figure shows the response of cumulated interventions (in billion USD) and the USD/JPY exchange rate (in \%) to an intervention shock of one standard deviation over a horizon of 250 trading days, along with $90 \%$ confidence bands from 200 bootstrap replications based on a SVAR(50) identified with an external instrument.
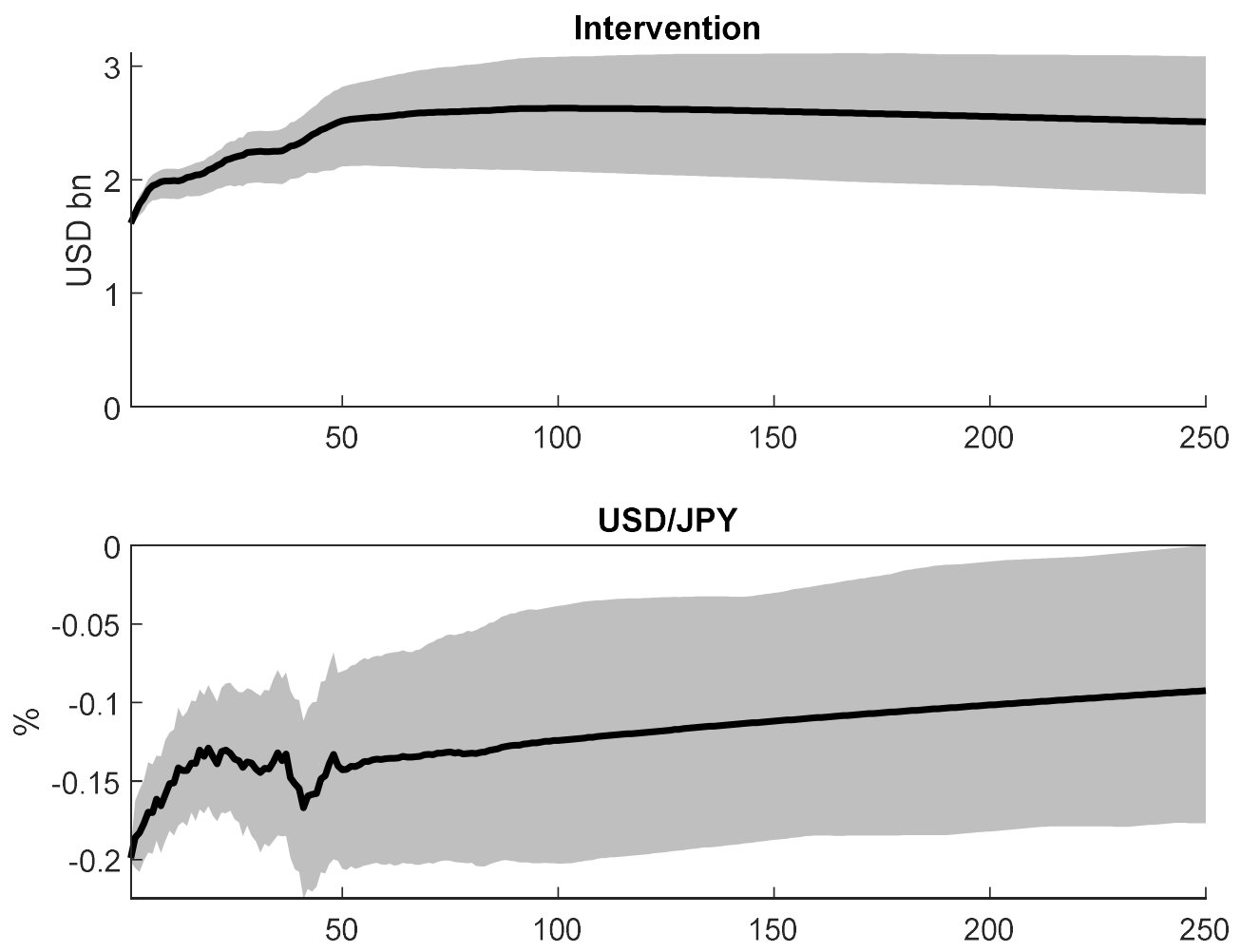


\section{Figure 3: Effects of FX intervention shocks in Japan on other currencies}

The figure shows the responses of cumulated interventions and nominal exchange rates of the Japanese Yen to a one standard deviation intervention shock over a horizon of 100 trading days, along with their $90 \%$ confidence bands from 200 bootstrap replications, based on a SVAR(50) identified with an external instrument.
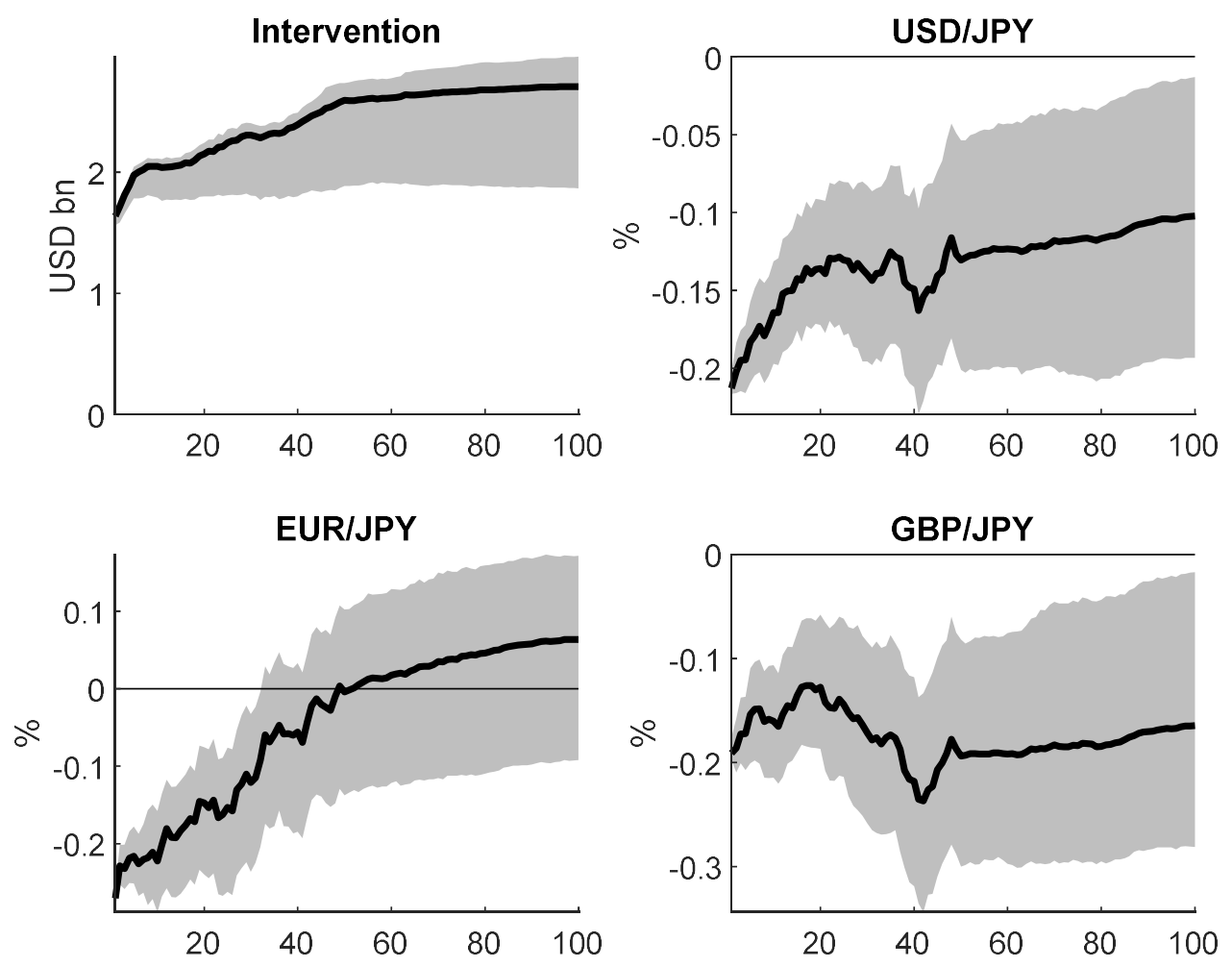

Table 2: Test for invertibility of SVAR identified with external instrument

The table shows $p$-values for a robust $F$-statistic testing the null hypothesis that the coefficients on 1 to 1-6 lags of the instrument are jointly equal to zero in each of the VAR equations of the extended model.

\begin{tabular}{ccccccccc}
\hline Lags & $\begin{array}{c}\text { Interv- } \\
\text { ention }\end{array}$ & $\begin{array}{c}\text { USD/ } \\
\text { JPY }\end{array}$ & $\begin{array}{c}\text { Int. rate } \\
\text { diff. }\end{array}$ & $\begin{array}{c}\text { Two- } \\
\text { year rate }\end{array}$ & $\begin{array}{c}\text { Five- } \\
\text { year rate }\end{array}$ & $\begin{array}{c}\text { Ten- } \\
\text { year rate }\end{array}$ & $\begin{array}{c}\text { Large } \\
\text { caps }\end{array}$ & $\begin{array}{c}\text { Small } \\
\text { caps }\end{array}$ \\
\hline 1 & 0.91 & 0.24 & 0.31 & 0.35 & 0.66 & 0.38 & 0.37 & 0.68 \\
2 & 0.36 & 0.32 & 0.59 & 0.63 & 0.17 & 0.07 & 0.08 & 0.20 \\
3 & 0.32 & 0.39 & 0.25 & 0.23 & 0.14 & 0.11 & 0.16 & 0.26 \\
4 & 0.47 & 0.46 & 0.30 & 0.18 & 0.07 & 0.05 & 0.13 & 0.20 \\
5 & 0.59 & 0.61 & 0.40 & 0.23 & 0.08 & 0.07 & 0.21 & 0.30 \\
6 & 0.71 & 0.70 & 0.51 & 0.32 & 0.11 & 0.08 & 0.30 & 0.41 \\
\hline
\end{tabular}


Figure 4: Responses of interest rates and stock prices to JPY-intervention shock

The figure shows the responses of different asset prices to an intervention shock of one standard deviation over a horizon of 100 trading days, along with their $90 \%$ confidence bands from 200 bootstrap replications based on a SVAR(50) identified with an external instrument.
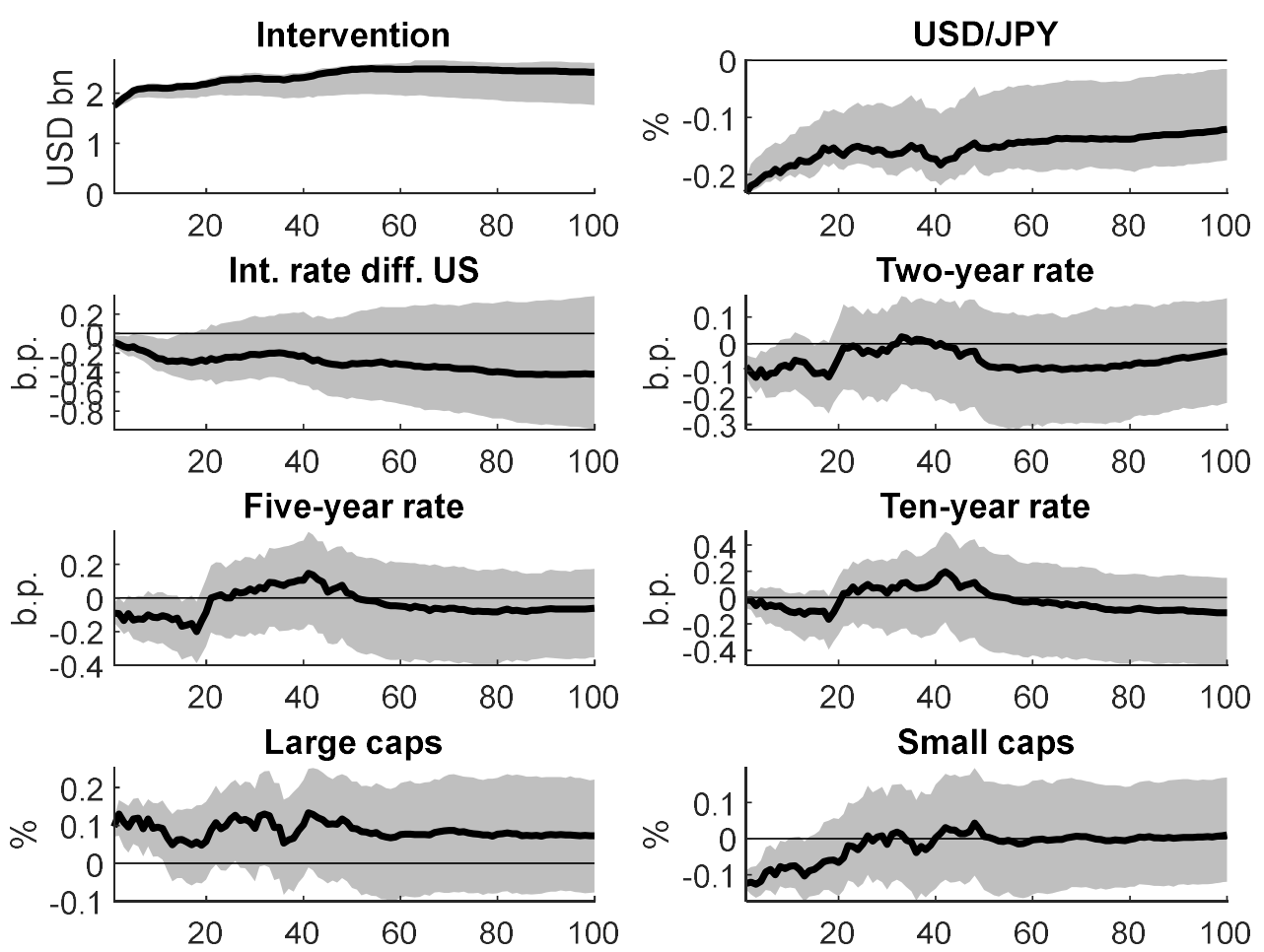

Table 3: Forecast error variance decomposition.

\begin{tabular}{ccccccccc}
\hline Horizon & $\begin{array}{c}\text { Inter- } \\
\text { vention }\end{array}$ & $\begin{array}{c}\text { USD/ } \\
\text { JPY }\end{array}$ & $\begin{array}{c}\text { Int. rate } \\
\text { diff. }\end{array}$ & $\begin{array}{c}\text { Two- } \\
\text { year rate }\end{array}$ & $\begin{array}{c}\text { Five- } \\
\text { year rate }\end{array}$ & $\begin{array}{c}\text { Ten-year } \\
\text { rate }\end{array}$ & $\begin{array}{c}\text { Large } \\
\text { caps }\end{array}$ & $\begin{array}{c}\text { Small } \\
\text { caps }\end{array}$ \\
\hline 1 & 94.9 & 11.5 & 0.1 & 0.2 & 0.1 & 0.0 & 0.5 & 0.8 \\
5 & 92.2 & 10.3 & 0.1 & 0.3 & 0.1 & 0.0 & 0.7 & 0.7 \\
10 & 89.9 & 9.4 & 0.2 & 0.2 & 0.2 & 0.0 & 0.7 & 0.5 \\
50 & 82.2 & 6.4 & 0.3 & 0.1 & 0.1 & 0.1 & 0.6 & 0.2 \\
100 & 78.3 & 5.2 & 0.4 & 0.2 & 0.1 & 0.1 & 0.5 & 0.1 \\
\hline
\end{tabular}


Figure 5: Historical decomposition of USD/JPY exchange rate and estimated intervention shocks

The upper panel shows the historical decomposition of the observed USD/JPY nominal exchange rate (solid line) and the exchange rate without the contribution of the intervention shocks (dashed line). The lower panel contains the estimated structural intervention shocks (thin line) and their cumulated version (thick line).

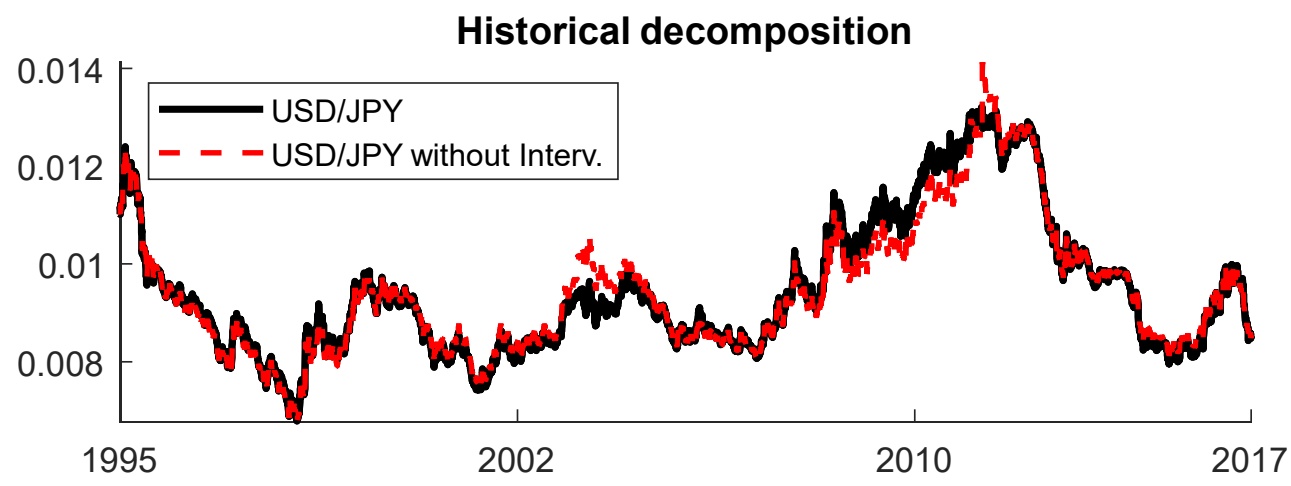

Intervention shocks

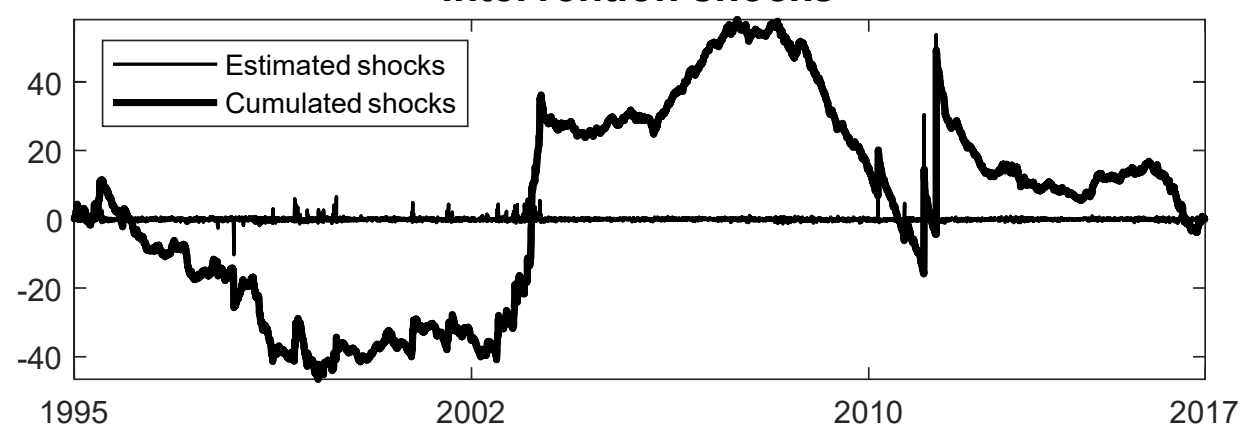




\section{Figure 6: Subsample estimates}

The figure shows the responses of the endogenous variables to an intervention shock of USD 9.35 billion, or JPY 1 trillion, over a horizon of 250 trading days based on a SVAR(50) identified with external instrument estimated over the full sample (solid line), along with $90 \%$ confidence bands, and the point estimates for different subsamples.
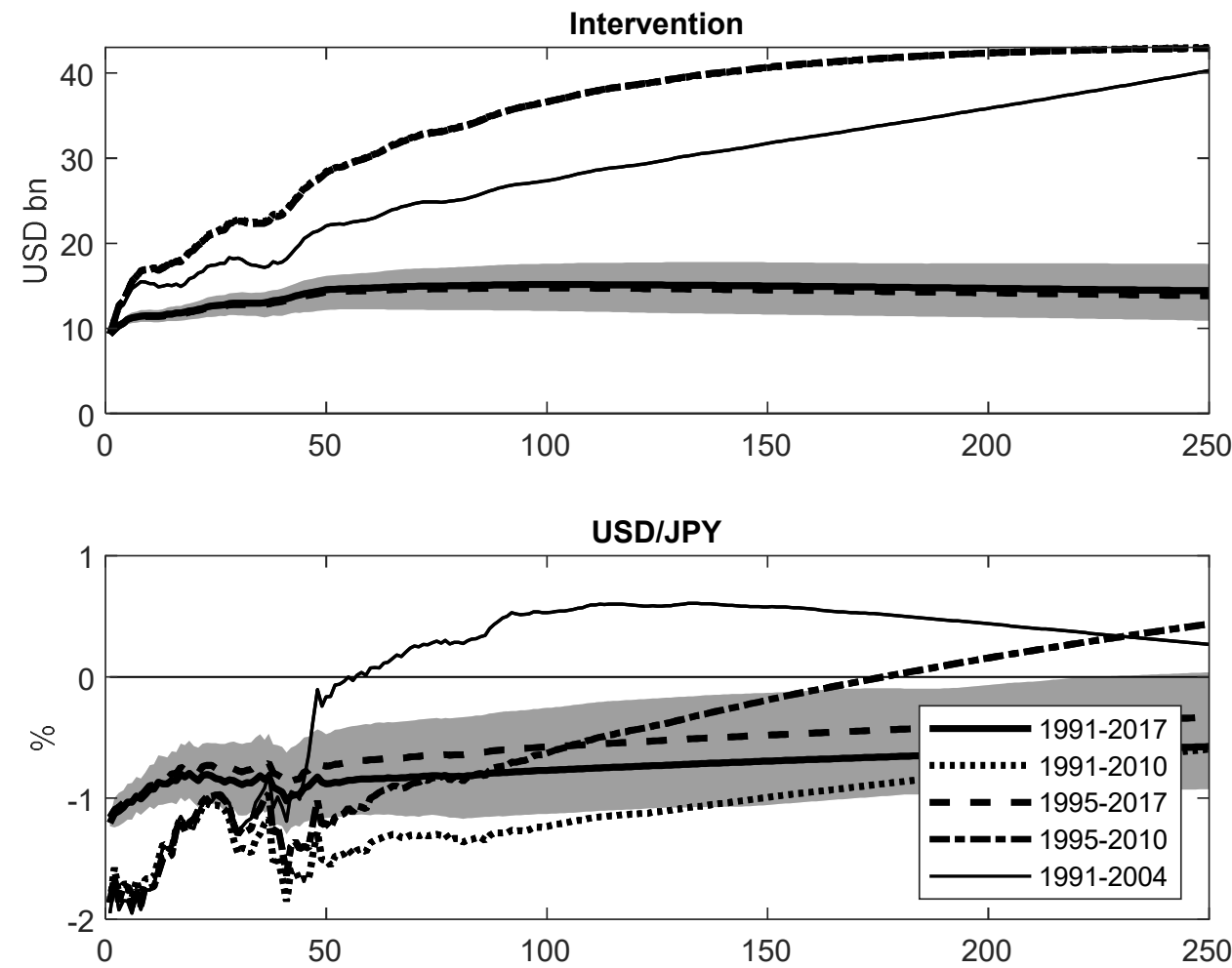


\section{Figure 7: Comparison of Proxy-SVAR and recursive identification}

The figure shows the responses of different asset prices to an intervention shock of one standard deviation over a horizon of 100 trading days based on a SVAR(50) identified with an external instrument (solid line) and based on a SVAR(50) identified recursively with the cumulated interventions ordered first (dashed line), along with their $90 \%$ confidence bands.
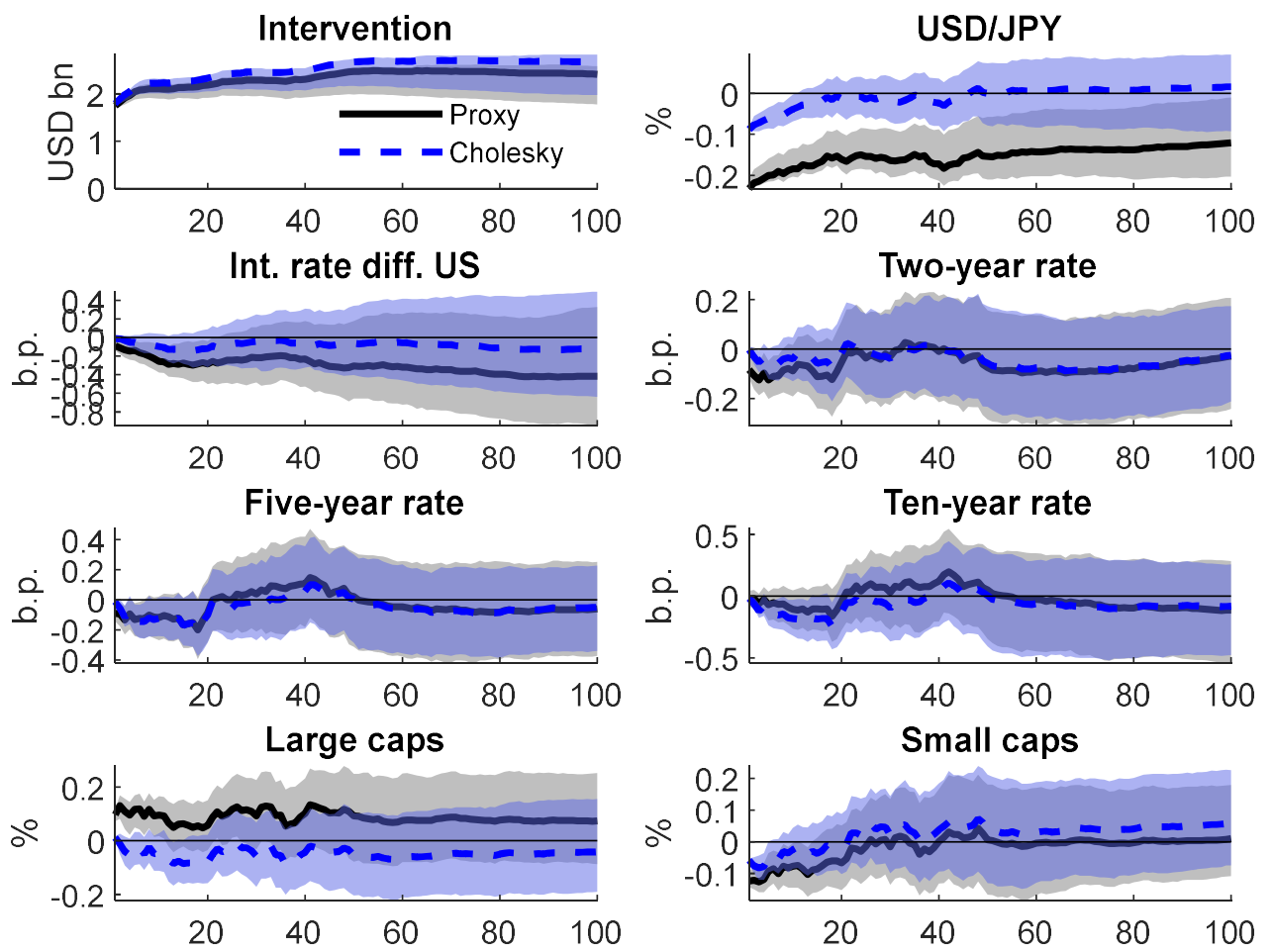

Table 4: Descriptive statistics for the US

\begin{tabular}{lcc}
\hline & All interventions & Instrument (start of sequence) \\
\hline Number of interventions & & \\
Number of interventions & 38 & 25 \\
Purchases of foreign currency & 7 & 6 \\
Sales of foreign currency & 31 & 19 \\
Unconditional probability & 0.006 & 0.004 \\
Conditional on previous intervention & 0.105 & 0 \\
& & \\
In billion USD & & -0.33 \\
Average intervention & -0.38 & 0.41 \\
Average purchase & 0.36 & -0.57 \\
Average sale & -0.55 & -0.20 \\
Median intervention & -0.25 & 1.31 \\
Maximum purchase & 1.31 & 1.60 \\
Maximum sale & 1.60 & \\
\hline
\end{tabular}




\section{Figure 8: Technical decomposition of transmission channels}

The figure shows the responses of different asset prices to an intervention shock of one billion USDollar over a horizon of 100 trading days based on a SVAR(50) identified with an external instrument (solid line) and based on a SVAR(50) identified recursively with the cumulated first day interventions ordered first (dashed line), along with their 90\% confidence bands. The Proxy-SVAR estimates contain both the signaling and the portfolio balance channel, while the recursive SVAR arguably approximates the impact of the portfolio channel only.
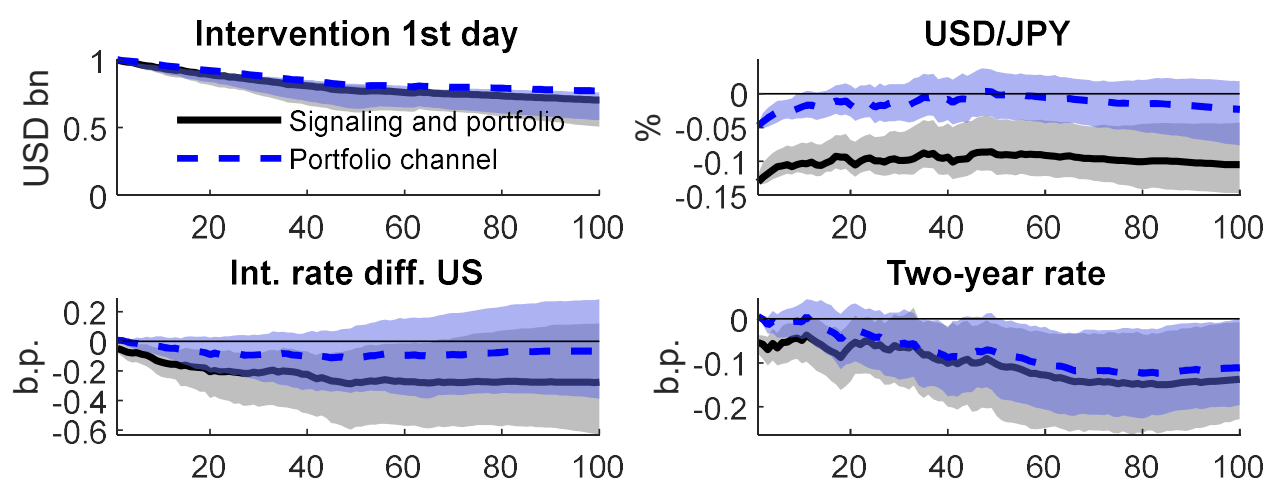

Five-year rate
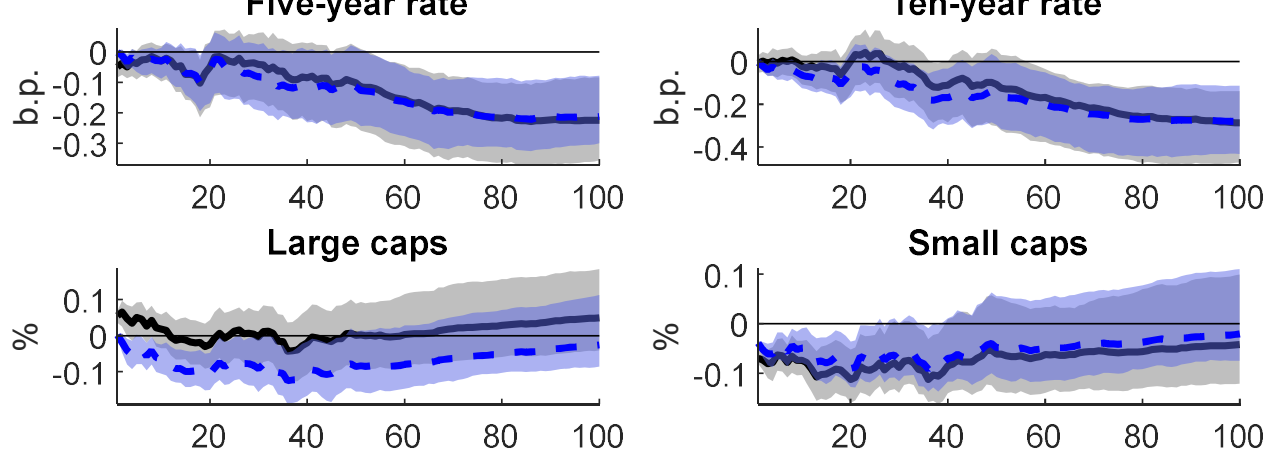


\section{Figure 9: Narrative decomposition of transmission channels}

The figure shows the responses of different asset prices to an FX intervention shock of one billion USDollar over a horizon of 100 trading days based SVARs(50) identified with an external instrument, along with their $90 \%$ confidence bands. The solid line shows the results when the non-censored instrument observations contain both an actual intervention and communication, approximating the composite effect of the portfolio and the signalling channel. The dashed line shows the results when the non-censored instrument observations contain only an actual intervention, approximating the impact of the portfolio effect in isolation.
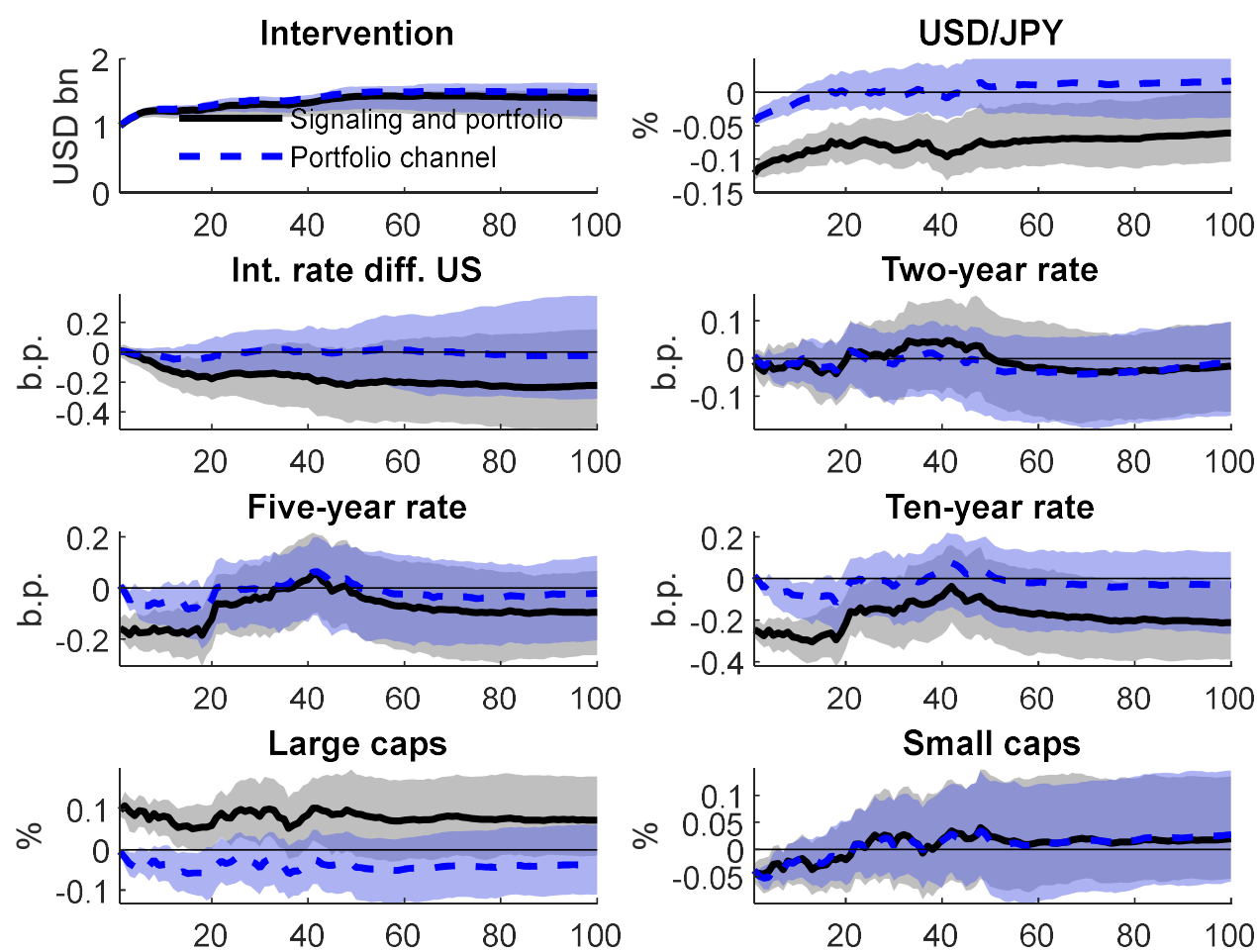
Figure 10: The dynamic effects of FX intervention shocks in the US

The figure shows the responses of the endogenous variables to an intervention shock of one standard deviation over a horizon of 50 trading days based on a SVAR(50) identified with an external instrument, along with $90 \%$ confidence bands using 200 bootstrap replications.

Table 5: Forecast error variance decomposition for the US.

\begin{tabular}{ccccccccc}
\hline Horizon & $\begin{array}{c}\text { Inter- } \\
\text { vention }\end{array}$ & $\begin{array}{c}\text { USD/ } \\
\text { EUR }\end{array}$ & $\begin{array}{c}\text { Int. rate } \\
\text { diff. }\end{array}$ & $\begin{array}{c}\text { Two- } \\
\text { year rate }\end{array}$ & $\begin{array}{c}\text { Five- } \\
\text { year rate }\end{array}$ & $\begin{array}{c}\text { Ten-year } \\
\text { rate }\end{array}$ & $\begin{array}{c}\text { Large } \\
\text { caps }\end{array}$ & $\begin{array}{c}\text { Small } \\
\text { caps }\end{array}$ \\
\hline 1 & 99.6 & 0.6 & 0.0 & 0.0 & 0.0 & 0.0 & 0.0 & 0.0 \\
5 & 99.2 & 0.4 & 0.5 & 0.2 & 0.2 & 0.2 & 0.0 & 0.0 \\
10 & 98.5 & 0.7 & 0.8 & 0.4 & 0.3 & 0.2 & 0.1 & 0.0 \\
50 & 90.6 & 1.1 & 2.9 & 0.1 & 0.2 & 0.4 & 0.1 & 0.1 \\
100 & 83.3 & 1.5 & 5.1 & 0.1 & 0.3 & 0.7 & 0.5 & 0.4 \\
\hline
\end{tabular}




\section{APPENDIX \\ Appendix A. Robustness checks (detailed version of Section 4.4)}

In this appendix, we perform four analyses to see how the results are affected by our definition of the instrument. First, we use a policy reaction function approach to clean the instrument. Second, we redefine intervention sequences using a stricter criterion. Third, we exclude coordinated interventions. In all cases, we scale the policy shock to one standard deviation of the baseline model for comparability and focus on the bivariate model for brevity. Fourth, we perform a counterfactual placebo analysis by purposely applying a "useless" instrument variable in our Proxy-SVAR approach, i.e. the second day of an intervention episode (instead of the first day).

Policy reaction function. We argue that the first day of any intervention sequence is largely exogenous. This implies that - although market participants form expectations about future interventions - it is difficult to forecast these days. In order to capture this reasoning, we use the reaction function for Japanese FX interventions proposed by Ito and Yabu (2007). Assuming that interventions being explained by this approach can be expected, we take the (unexplained) residual as instrument in our Proxy-SVAR. These values deviate at most $+/-7 \%$ from the values of the categorical variable $(1,0,-1)$ used in the baseline specification. Thus, it is not a surprise that the estimated intervention impact, shown by the solid line in Figure A1, is graphically difficult to distinguish from the impact relying on our baseline instrument. We conclude that the exact intervention day is actually hard to anticipate.

Longer intervention sequences. Next, we evaluate whether our argumentation for instrument exogeneity based on the institutional design for intervention policy relates to the length of an intervention sequence. Ex ante, it is conceivable that our assumption is better suited 
for longer sequences with larger volumes than for shorter and smaller sequences, as the former might require more preparatory work and coordination between the Bank of Japan and the Ministry of Finance. To test this hypothesis, we re-define intervention sequences as consisting of at least two intervention days within five trading days. We leave the definition of the start of a sequence unchanged such that there are no interventions in the preceding five trading days. The dotted line in Figure A1 shows that the estimated effect of intervention shocks based on the modified instrument is qualitatively the same as for the baseline definition of the instrument or the cleaned instrument. It remains statistically significant. However, the effect decreases substantially, both upon impact and thereafter. Ex post, we interpret the smaller estimate as reflecting selection bias in the redefinition of the instrument. Using only longer spells seems to imply focusing on sequences that are less successful initially and, therefore, are continued longer, such that the estimated impact based on this subset of non-censored instrument observations declines.

Internationally coordinated interventions. Finally, we assess how the baseline results change when excluding coordinated interventions. It is a stylized fact that these interventions have larger effects. For data availability reasons, we exclude days from the sample when US monetary authorities also intervened. There are seven such days in the sample. Indeed, the dashed line shows that the estimated impact on the exchange rate decreases, but the depreciation remains statistically significant for 45 days.

Placebo test. To see which conditions would invalidate our approach, we use an alternative and ex ante conceivably useless instrument. Specifically, we employ the second day of the intervention sequences that we identify for the baseline results as instrument for intervention shocks, instead of the first day of these sequences. As we argued before, the decision to continue a sequence is more likely to depend on current market conditions which reflect the success of the initial intervention. Hence, we expect the results to be affect by 
endogeneity. Figure A2 shows that this is indeed the case. An intervention shock of the same sign as in the baseline model now leads to an appreciation of the currency, instead of a depreciation, and significant increases in interest rates of different maturities. This placebo test suggests that our identification strategy actually works for latent intervention shocks and that our results are not by chance. 


\section{Figure A1: Impulse responses for modified instruments}

The figure shows the responses of the endogenous variables to an intervention shock of one standard deviation in the baseline model for 50 trading days based on a SVAR(50) identified with modified external instruments, along with $90 \%$ confidence bands using 200 bootstrap replications. The solid line refers to an instrument cleaned through a policy function approach, the dotted line to longer intervention sequences including at least one additional intervention in the five days following the initial intervention, and the dashed line to an instrument that excludes coordinated interventions.
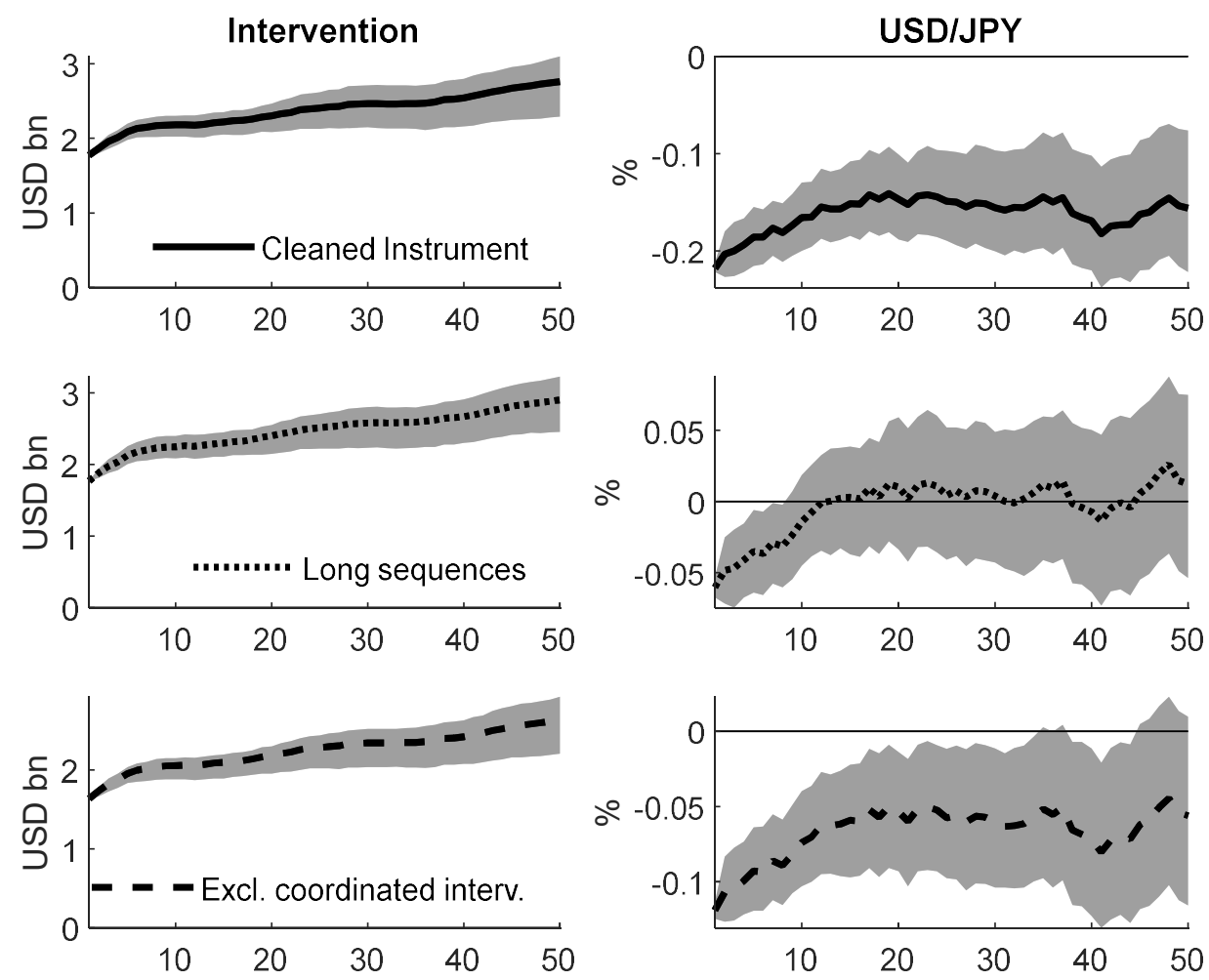


\section{Figure A2: Placebo test using second day of intervention sequence}

The figure shows the responses of different asset prices to an intervention shock of one standard deviation over a horizon of 100 trading days, along with their $90 \%$ confidence bands from 200 bootstrap replications, based on a SVAR(50) identified with an external instrument. The instrument is the second day of an intervention sequence.
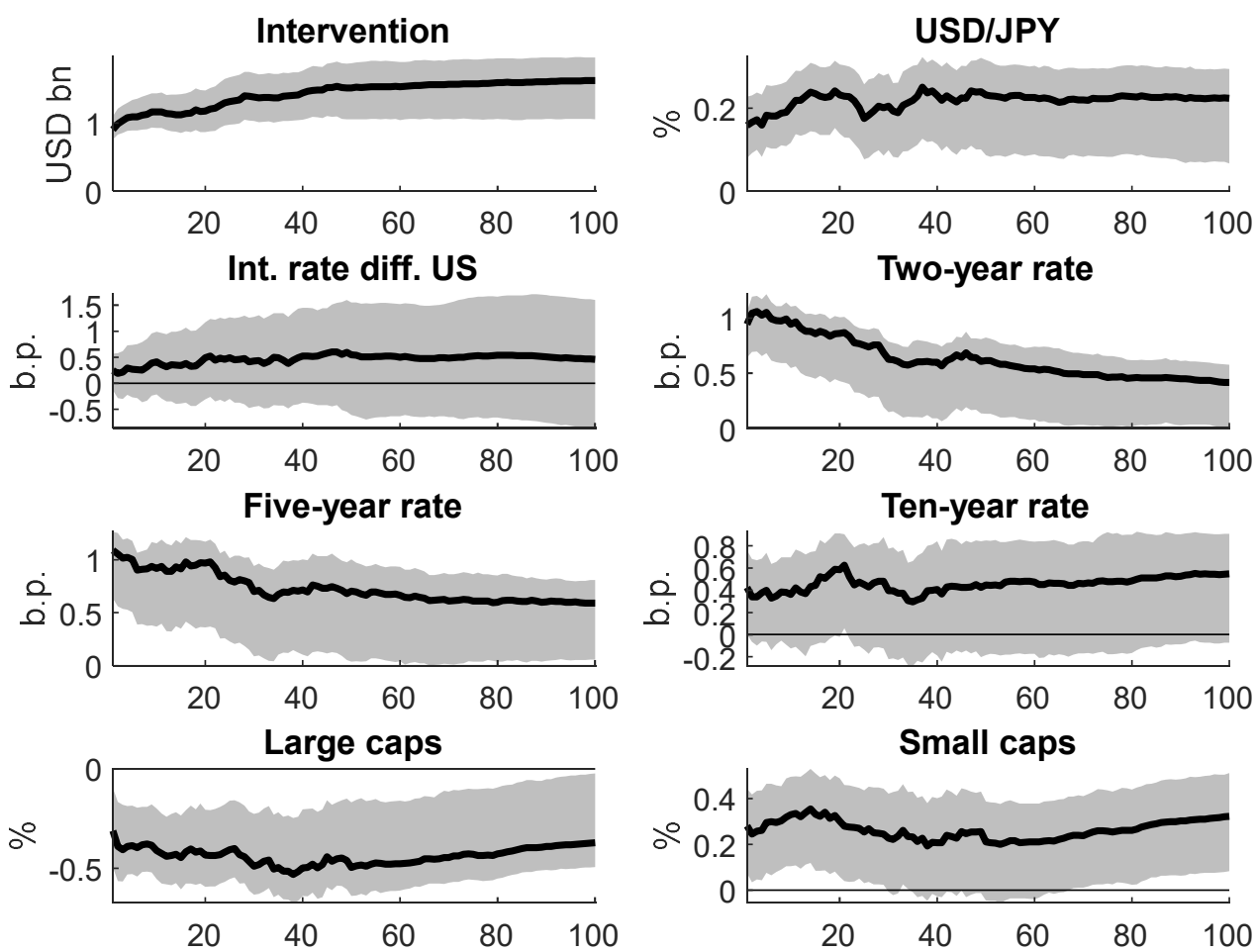


\section{Appendix B. Further sensitivity analyses (detailed version of Section 4.5)}

In this appendix, we summarize the results from an extensive sensitivity analysis. They demonstrate that our main results are robust and tend to provide a conservative, that is, lower bound estimate of the effect of FX interventions. In detail, we exclude either the weekday or month dummies from the set of exogenous variables, or include either a linear trend or year dummies. The differences are so small that they are invisible graphically, so we do not report them in a separate figure in the Appendix. Furthermore, we use the following different numbers of lags of the endogenous variables: 10, 20, 30, 40, 60, and 70. Outcomes presented in Figure $\underline{B} 1$ show that there are no major qualitative modifications to the benchmark results.

Next, we consider alternative definitions of our instrument. On the one hand, we change the definition of an intervention sequence by shortening the time-window before the start of a new sequence without interventions from 5 days in the baseline specification to 4, 3, 2, 1, and 0 days, respectively. This increases the number of non-zero observation of the proxy up to 325 actual intervention days. But the corresponding Figure B2 shows that the impact decreases in the size of the disconnection window since the risk of defining continuation days of an earlier sequence as a new sequence increases. On the other hand, we use the actual intervention size, instead of a categorical variable indicating the direction of the intervention, which we winsorize at the $10 \%$ level to remove outliers. The estimated impact decreases slightly in absolute size but remains significant for about 100 trading days (see Figure B3).

Then, we consider further modifications of the sample. We cut 1, 2, 3, 4, and 5 years of observations both at the beginning and at the end of the sample, and estimate the model on all 25 different subsamples. The results shown in Figure B4 indicate that the estimated impact is larger when excluding more recent years, but that the effect is of similar order of magnitudes across subsamples. 
Finally, regarding statistical inference, we use an alternative bootstrap methodology, i.e. the residual-based moving block bootstrap proposed by Jentsch and Lunsford (2019) for ProxySVARs as an alternative to the wild bootstrap. Following the suggestion of the authors, we set the block length to 45 , given our sample size, perform 1,000 replications, and focus on $68 \%$ confidence bands as this bootstrap is known to produce much wider confidence bands. Additionally, we report $90 \%$ error bands. Figure B5 shows that our main results are robust. There is a depreciation of the currency that is statistically significant for more than two quarters according to the $68 \%$ confidence bands and for about one quarter when looking at the $90 \%$ intervals. The impact on interest rates is largely insignificant, but stock prices respond significantly based on the $68 \%$ level for a few days following the shock. 


\section{Figure B1: Robustness to using alternative lag length}

The figure shows the responses of the endogenous variables to an intervention shock of one standard deviation over a horizon of 100 trading days based on a $\operatorname{SVAR}(p)$, for $p=10,20,30,40,60,70$ identified with an external instrument, along with $90 \%$ confidence bands using 200 bootstrap replications for the baseline specification with $p=50$.
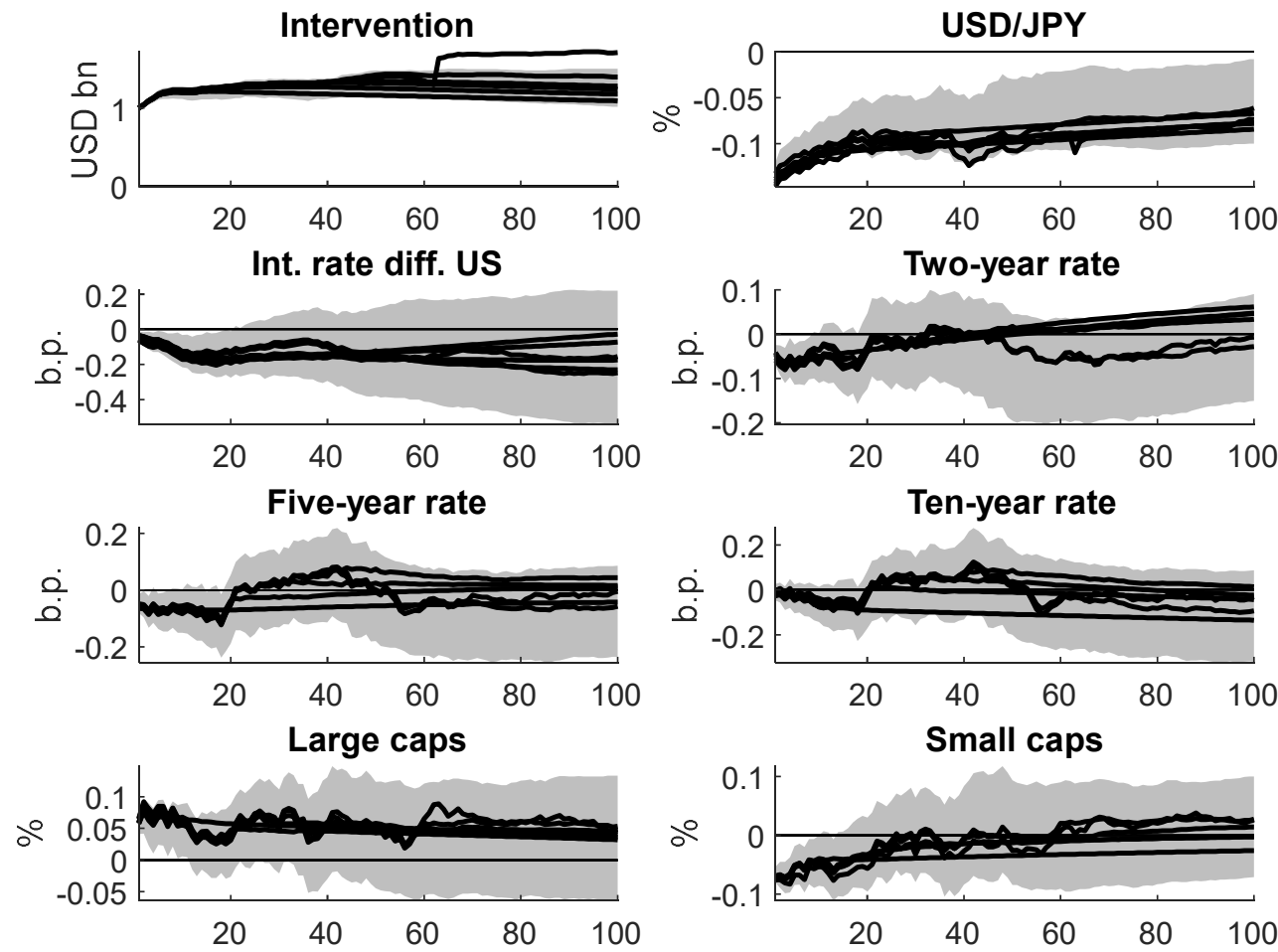


\section{Figure B2: Robustness to alternative definition of intervention sequence}

The figure shows the responses of the endogenous variables to an intervention shock of one standard deviation over a horizon of 100 trading days based on a SVAR(50) identified with an external instrument using a 1,2,3, and 4 day disconnect between actual interventions to define a new intervention sequence, along with $90 \%$ confidence bands using 200 bootstrap replications for the baseline specification using a 5-day disconnect.
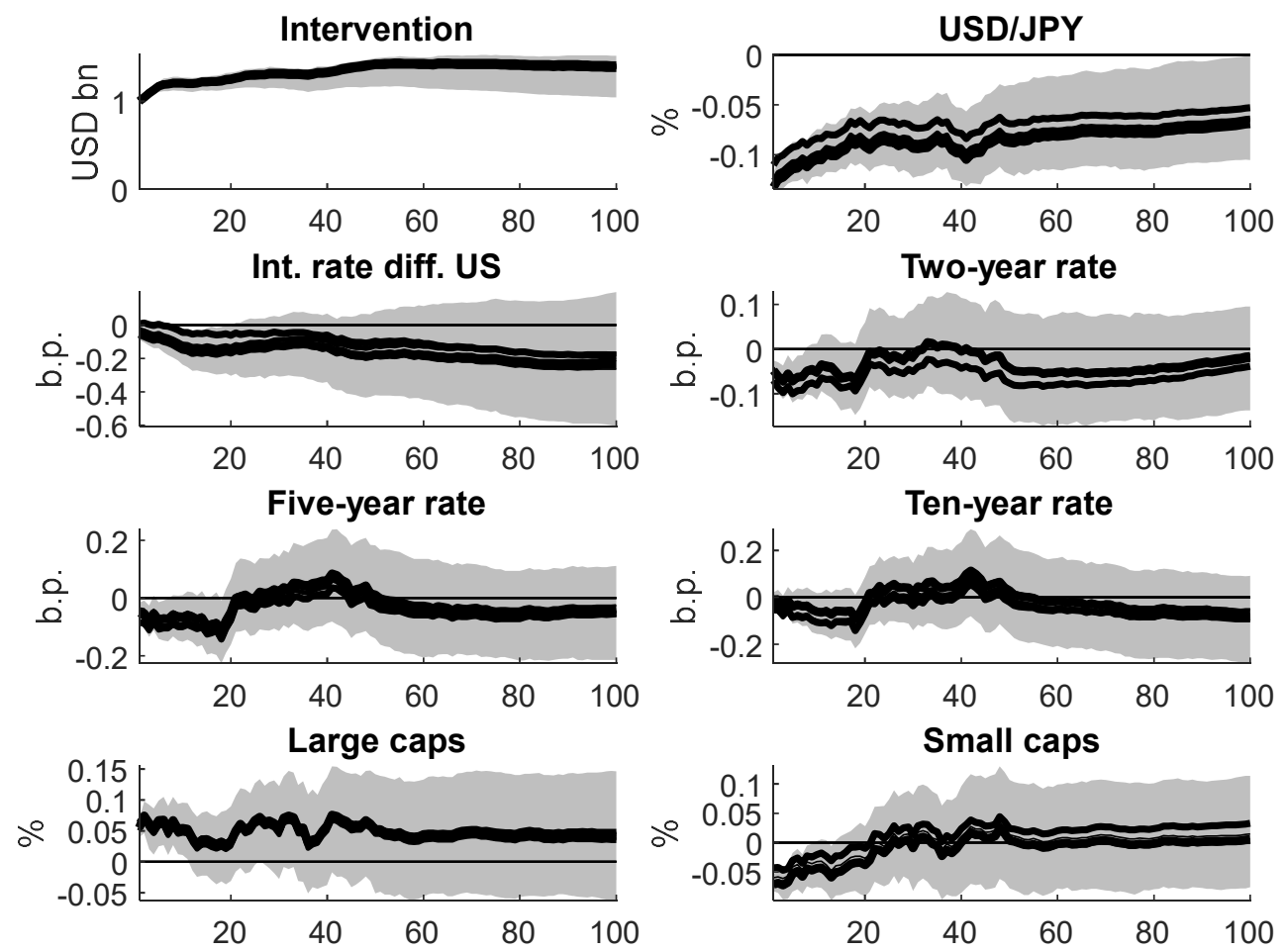


\section{Figure B3: Robustness to using intervention volume as instrument}

The figure shows the responses of the endogenous variables to an intervention shock of one standard deviation over a horizon of 100 trading days from an SVAR(50) identified with an external instrument, which is based on the $10 \%$-Winsorized intervention volume on the first day of an intervention sequence, along with $90 \%$ confidence bands using 200 bootstrap replications.
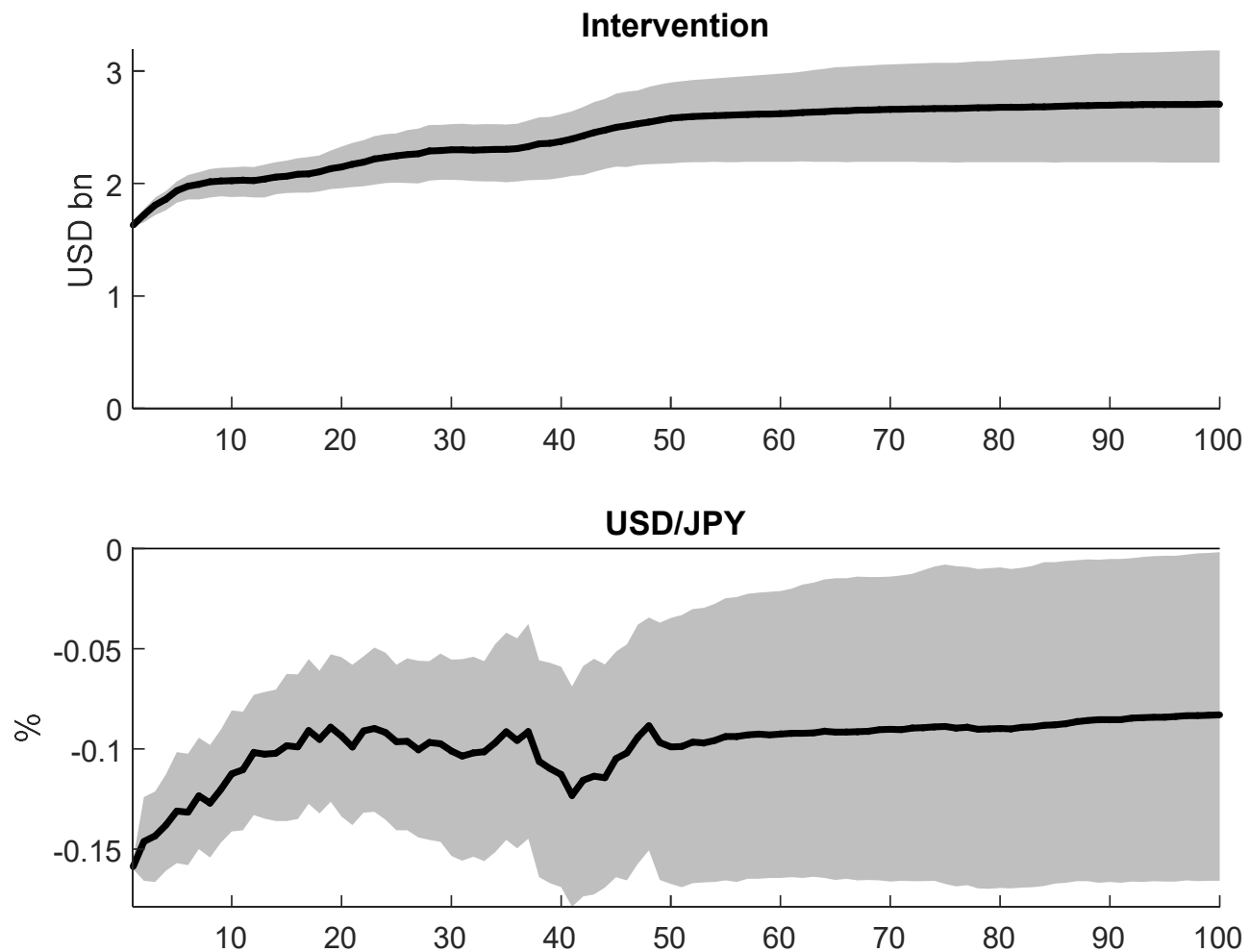


\section{Figure B4: Robustness in subsamples}

The figure shows the responses of the endogenous variables to an FX intervention shock of one standard deviation over a horizon of 100 trading days from an Proxy-SVAR(50) in 25 subsampled constructed by cutting $1,2,3,4$, and 5 years at the start or the end of the sample, along with $90 \%$ confidence bands of the baseline specification using the full sample and 200 bootstrap replications.
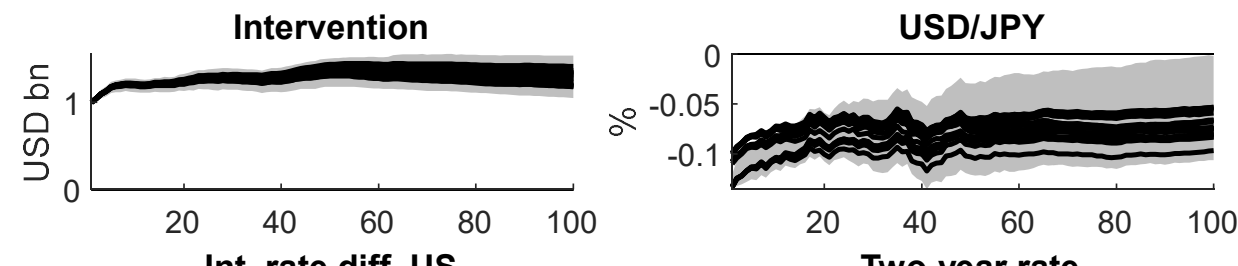

Int. rate diff. US
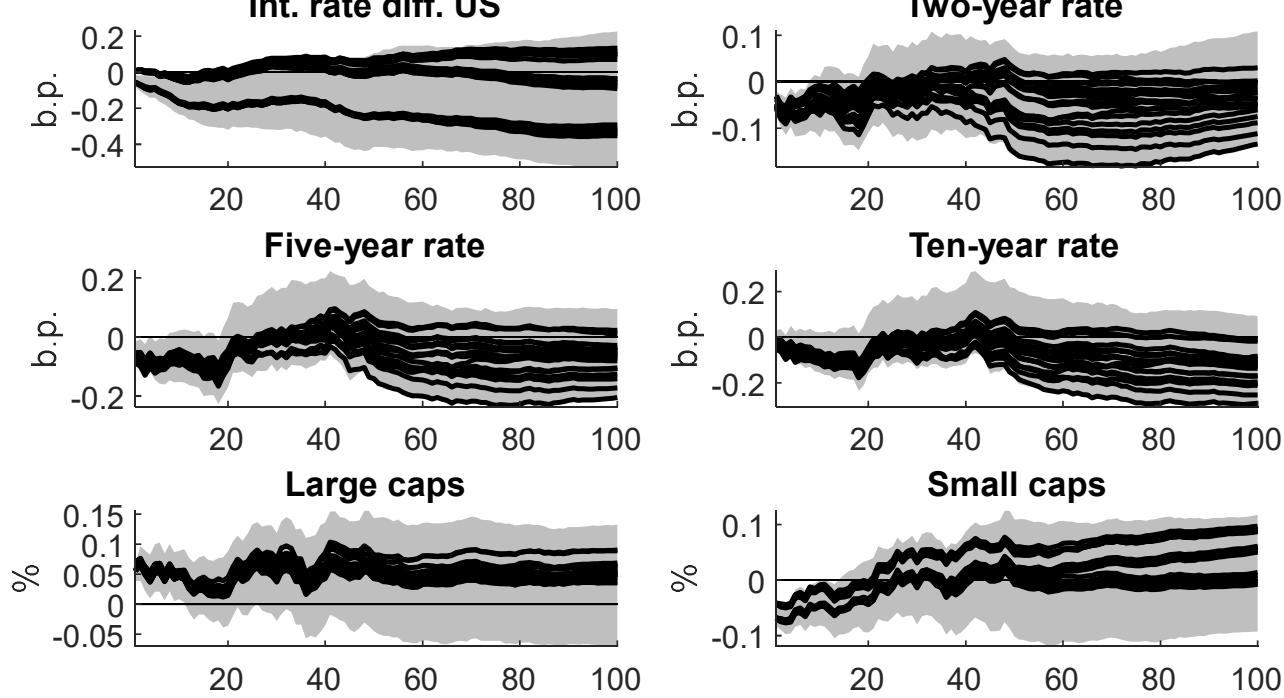


\section{Figure B5: Robustness to an alternative bootstrap procedure}

The figure shows the responses of the endogenous variables to an FX intervention shock of one standard deviation over a horizon of 100 trading days from an Proxy-SVAR(50), along with 90\% (dark grey) and $68 \%$ (light grey) confidence bands based on a residual-based moving block bootstrap using 1,000 replications.
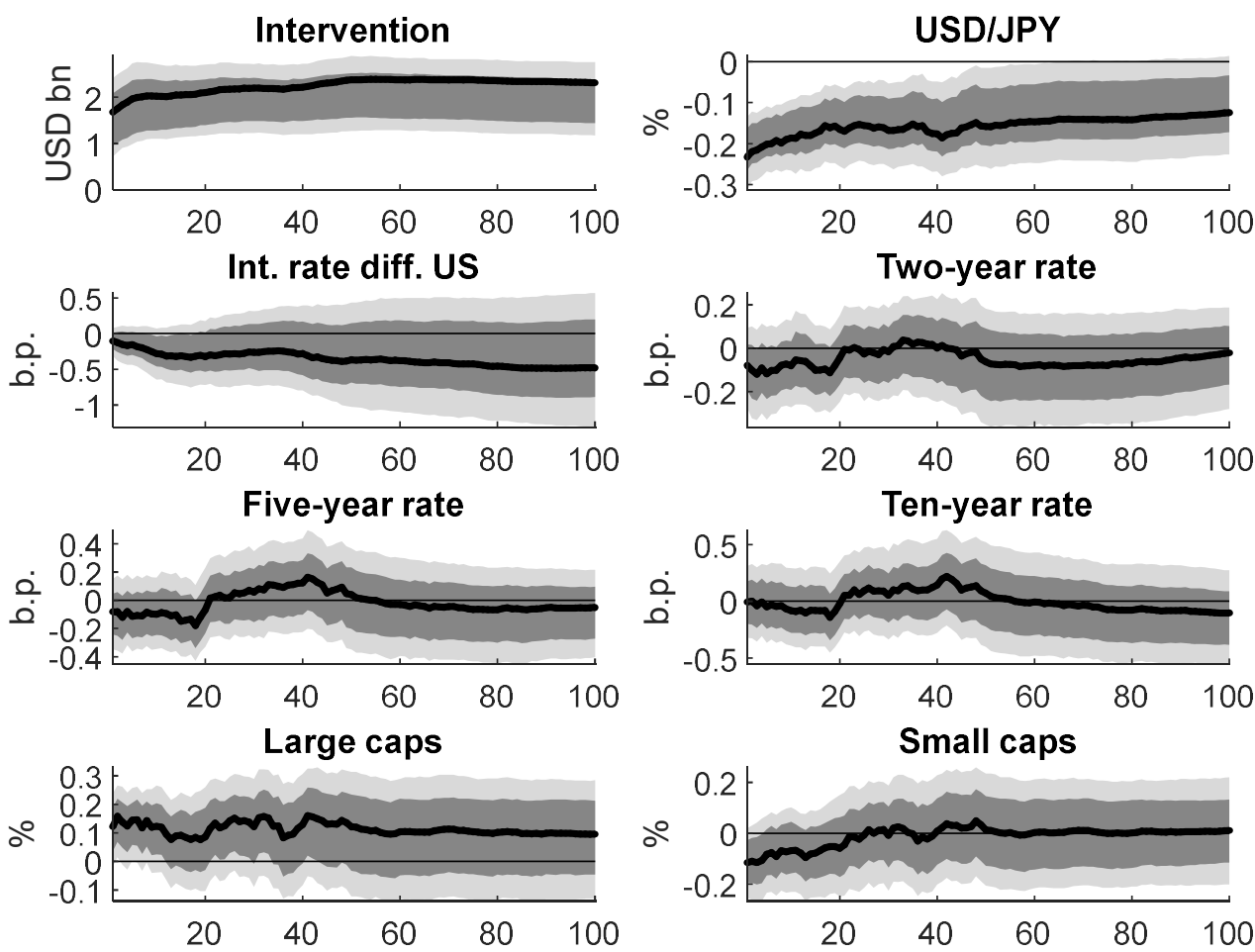


\section{Appendix C. Evidence for the Euro Area and UK (extension to Section 5)}

Finally, we present some tentative evidence for the Euro Area and the UK. Starting with the Euro Area, the European Central Bank (ECB) intervened only during two episodes. The first episode comprises four intervention days in fall of 2000, shortly after its inception, when the Euro depreciated continuously against the USD amid uncertainty about the monetary policy of the newly created central bank and strong US growth. The second episode corresponds to a single event on March 18, 2011. Several major central banks sold JPY to weaken the currency, which appreciated sharply due to a repatriation of funds of Japanese insurance companies and the closing of carry trades funded in JPY following the Tohoku earthquake.

The ECB does not officially publish the intervention days or volumes. However, there seem to have been only a few specific intervention days that can be dated relatively precisely based on financial press involving unofficial ECB statements and trading rumors. We identify these dates using Factiva news search. We use the same search to obtain approximations of the implied volumes, which were estimated by market participants and partly communicated unofficially by ECB members in media articles. For the intervention on September 22, 2000, we assume USD sales worth 2.5 billion based on Roussel et al. (2000). ${ }^{8}$ For November 3 and 6, 2000, we assume USD sales totaling 1.2 billion, drawing on Tannenbaum (2000). We found no information about the intervention volume on November 9, 2000, so we simply set it to the same size as the previous two intervention days, that is, sales of USD 0.6 billion. Finally, for March 18, 2011, we assume sales of JPY worth USD 0.3 billion based on Suoninen (2011).

\footnotetext{
${ }^{8}$ The exact references are as follows: Roussel, Edward, Sonja Dieckhoefer, Tom Kohn, Hellmuth Tromm and Vincent del Giudice. 2000. G-7 Nations Intervene for First Time to Boost Euro (Update 7), Bloomberg News (BN), Sep. 09, 2000; Suoninen, Sakari. 2011. ECB Forex Reserves Rise After Yen Intervention - Reuters News. Thomson Reuters Eikon, Mar. 29, 2011; Tannenbaum, Mark. 2000. Euro Falls as Appeal of U.S. Economy Outweighs ECB Purchases. Bloomberg News (BN), Nov. 6, 2000.
} 
As before, we use an indicator for the first day of a sequence as instrument based on the five-day criterion, implying that we have three non-censored observations for the proxy. Given this limited number, we set the lag length to 25 and focus on the bivariate model containing the cumulated intervention series and the exchange rate. Moreover, we start the analysis with the inception of the Euro on January 1, 1999.

The left column of Figure $\mathrm{C} 1$ shows the responses of the intervention level and the nominal exchange rate vis-à-vis the USD to an intervention shock of one standard deviation. As there is some persistence in the intervention data due to the sequence in November 2000, the cumulated interventions peak after about one trading week and then revert slowly to trend. The Euro depreciates significantly upon impact, weakening by roughly 5 basis points. Thereafter, it remains below trend for 5 trading weeks. For the first three weeks the depreciation is statistically significant.

Next, we turn to the UK. The Bank of England publishes intervention dates and volumes. We limit the analysis to the period 1994 onwards to exclude the extraordinary FX market conditions and interventions related to the speculative attacks against the British Pound in the early 1990s. This data limitation implies that we now have only two actual interventions in the sample. Therefore, we keep the reduced lag length and the bivariate model as used for the Eurocase. Moreover, we analyze the EUR/GBP exchange rate because the interventions occurred in this particular market. The right column of Figure 10 shows that the intervention shock corresponds to a purchase of Euros worth USD 2 million. The unexpected intervention leads to an immediate weakening of the Pound, which drops by roughly 2 basis points. The currency remains significantly below trend for about two weeks, and thereafter returns to the level where it would have been without the shock.

In summary, we find that the cases of Euro Area and UK interventions in the FX market tend to support the experience of Japan and the US, despite serious data limitations. While the 
pattern of observations is qualitatively similar across countries, the intervention impact appears stronger for the US, Euro Area, and UK than for Japan.

\section{Figure C1: The effects of FX intervention in the Euro Area and UK}

The figure shows the responses of the endogenous variables to an intervention shock of one standard deviation over a horizon of 25 trading days based on a bivariate SVAR(25) identified with an external instrument, along with $90 \%$ confidence bands using 200 bootstrap replications, for the Euro Area (left column, solid lines) and for the UK (right column, dashed lines).
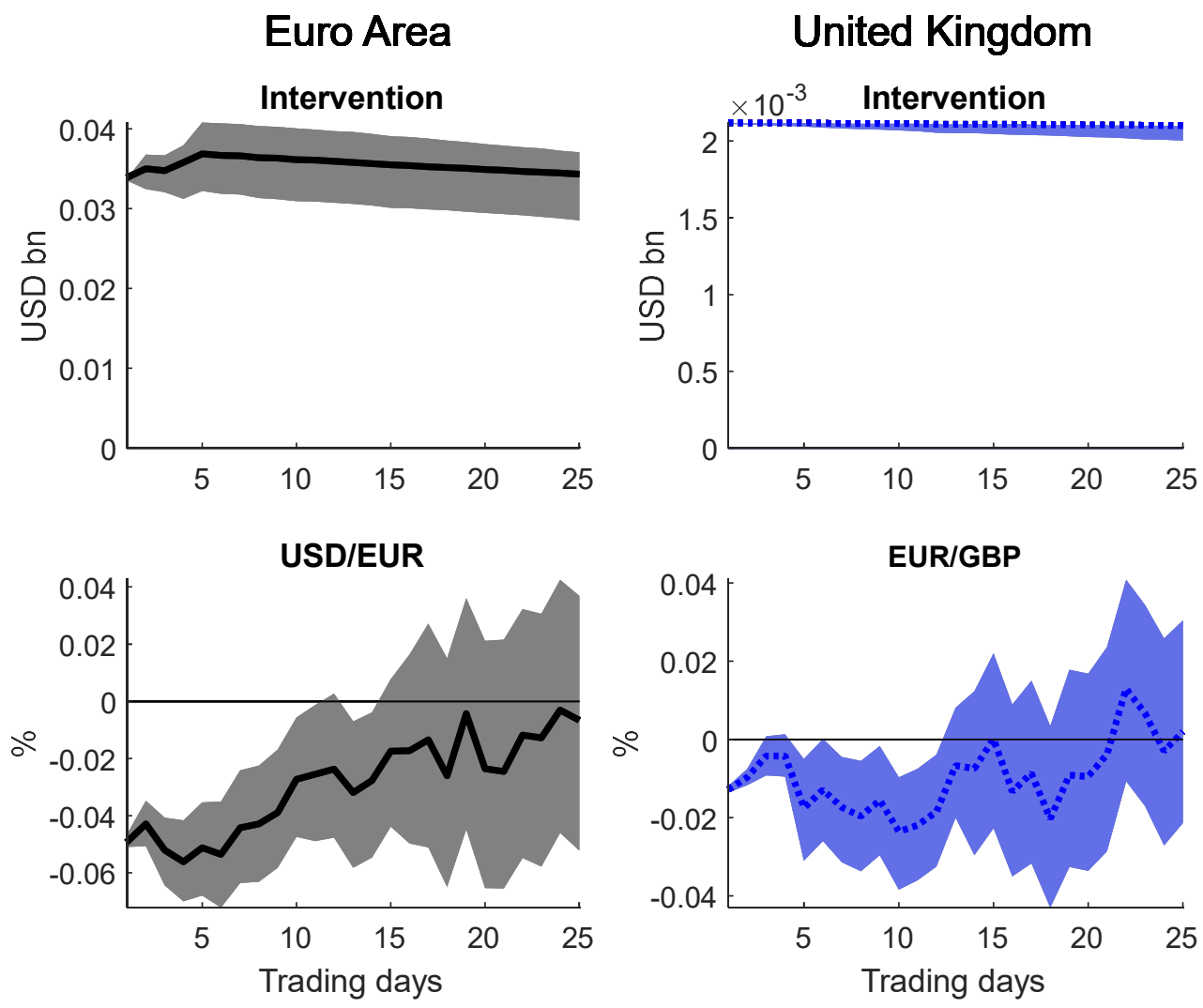